\title{
MEASUREMENT AND ANALYSIS OF CRITICAL CTOA FOR AN ALUMINUM ALLOY SHEET
}

D. S. Dawicke, M. A. Sutton, J. C. Newman, Jr., and C. A. Bigelow

(NASA-TM-109024) MEASUREMENT AND ANALYSIS OF CRITICAL CTOA FOR AN

N94-15948 ALUMINUM ALLOY SHEET (NASA) 33 p

\section{SEPTEMBER 1993}

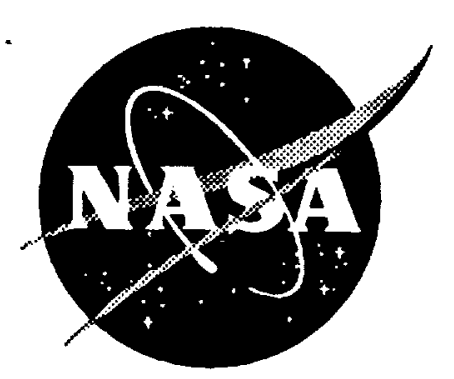

National Aeronautics and Space Administration

LANGLEY RESEARCH CENTER

Hampton, Virginla 23681-0001 
$\Rightarrow=0 \quad 0$

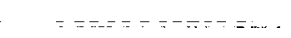

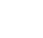




\title{
MEASUREMENT AND ANALYSIS OF CRITICAL CTOA FOR AN ALUMINUM ALLOY SHEET
}

\author{
D. S. Dawicke ${ }^{1}$, M. A. Sutton, ${ }^{2}$ J. C. Newman, Jr. ${ }^{3}$, and C. A. Bigelow ${ }^{3}$
}

\begin{abstract}
The stable tearing behavior of thin sheets of 2024-T3 aluminum alloy was investigated for middle crack tension, $M(T)$, and compact tension, $C(T)$, specimens. The surface crack-tip opening angle (CTOA), applied loads, crack extension, and local displacements were measured. A critical CTOA fracture criterion was incorporated into a twodimensional, elastic-plastic finite element code and used to simulate the experimental fracture behavior.

The CTOA measurements and observations of the fracture surfaces have shown that (a) large values for surface CTOA were observed for small crack extensions (less than the sheet thickness), (b) substantial tunneling of the crack was associated with small crack extensions, (c) crack tunneling in the $M(T)$ specimen was less than that observed in the $\mathrm{C}(\mathrm{T})$ configuration, (d) for larger crack extensions, the measured CTOA values were determined to be approximately $6^{\circ}$ for both the $M(T)$ and $C(T)$ configuration, and (e) for larger crack extensions, crack tunneling remained constant.

The two-dimensional finite element predictions of fracture behavior assumed a constant critical CTOA value of $6^{\circ}$ and accounted for local crack tip constraint with a plane strain core of elements ahead of the crack tip. The plane strain core extended $5 \mathrm{~mm}$ above the crack plane. The simulations were within $\pm 4 \%$ of the maximum applied load for the C(T) tests and within $2 \%$ for the $\mathrm{M}(\mathrm{T})$ tests.
\end{abstract}

\section{Nomenclature}

$\begin{array}{ll}\text { a } & \text { Crack length } \\ \Delta \mathrm{a} & \text { Crack extension } \\ \mathrm{a}_{\mathrm{i}} & \text { Interior crack length } \\ \mathrm{a}_{\mathrm{s}} & \text { Surface crack length } \\ \mathrm{B} & \text { Specimen thickness } \\ \mathrm{d} & \text { Minimum element size along the line of crack extension } \\ \mathrm{E} & \text { Elastic modulus } \\ \mathrm{K}_{\mathrm{I}} & \text { Mode I stress-intensity factor } \\ \mathbf{P} & \text { Applied load } \\ \mathrm{R} & \text { Stress ratio } \\ \mathrm{S} & \text { Applied stress } \\ \mathbf{u} & \text { Displacement perpendicular to the direction of loading } \\ \mathbf{v} & \text { Displacement parallel to the direction of loading } \\ \text { w } & \text { Specimen width } \\ \delta & \text { Crack-tip opening displacement } \\ \delta_{0} & \text { Crack-tip opening displacement measured at the crack faces at a distance of } 1 \mathrm{~mm}\end{array}$

1 Senior Scientist, Analytical Services and Materials, Inc., Hampton, VA 23666.

${ }^{2}$ Professor, University of South Carolina, Columbia, SC 29208.

${ }^{3}$ Senior Scientist, NASA Langley Research Center, Hampton, VA 23681-0001. 
$\delta_{45} \quad$ Crack-tip opening displacement where $45^{\circ}$ lines intercept the crack faces

$\delta_{5} \quad$ Crack-tip opening displacement measured $\pm 5 \mathrm{~mm}$ above and below the crack faces at a distance of $1 \mathrm{~mm}$ behind the original fatigue crack tip

$\delta_{c} \quad$ Critical crack-tip opening displacement

$\varepsilon \quad$ Strain

$\sigma \quad$ Stress

$v \quad$ Poisson's ratio

$\Psi \quad$ Crack-tip opening angle

$\Psi_{c} \quad$ Critical crack-tip opening angle

\section{Introduction}

The aging of the commercial transport aircraft fleet has increased concern for fatigue damage developing in pressurized fuselage structures. One of the objectives of the NASA Aircraft Structural Integrity Program [1] is to develop methodologies to predict the residual strength of cracked, thin-skinned, pressurized fuselage structures. The approach taken is to develop a local fracture criterion that can be used with shellcode finite element analyses. The fracture criterion and finite element analyses should be able to predict large amounts of stable crack growth under conditions of large-scale yielding in thin sheet materials. Numerous fracture mechanics-based parameters have been proposed to characterize stable crack growth, including the average crack opening angle (COA) [2], crack-tip opening angle (CTOA) [3,4], crack-tip opening displacement (CTOD) [5-7], energy release rate [8], crack-tip strain [9] and J-integral resistance curves [10-13].

Of course, a valid crack growth criterion should be reasonably independent of specimen geometry. Thus, the effects of both loading and, possibly, stress state in the crack tip region need to be considered. To quantify the effects of through-the-thickness stresses, Hom and McMeeking [14] analyzed sharp notches (a ratio of thickness to notch radius of 5-10) using finite deformation theory plasticity and Newman, et. al [15] analyzed stationary cracks using small strain plasticity. Both found that substantial constraint is built up through the thickness in thin materials prior to crack growth, with the hydrostatic stress at the mid-thickness nearly 2.5 times the value at the free surface. Thus, it is clear that cracks in thin sheets have complex, highly three-dimensional stress and strain fields prior to the onset of crack extension.

Radon and Leevers [16] have shown that, for a stationary crack in an elastic material, a compact tension specimen, $\mathrm{C}(\mathrm{T})$, will have higher constraint than a middle crack tension specimen, $M(T)$. Thus, during the initial stages of loading, it is reasonable to expect that differences in crack initiation and growth may occur in the two crack 
configurations. However, during stable crack growth, large scale plastic deformation occurs and the initial elastic constraint differences are reduced. In fact, using recent work by Yang, et. al. [17] it can be shown that constraint decreases for a plane strain, threepoint-bend specimen (having constraint similar to a $\mathrm{C}(\mathrm{T})$ specimen) undergoing fully plastic deformations prior to crack growth. Hence, if crack growth occurs under fully plastic conditions, the effects of in-plane constraint on the fracture parameter should be small.

Recently, Kobayashi and co-workers [18-24] completed a series of experiments on thin specimens to assess the validity of the J-integral resistance curves. Their work has shown that the surface displacements $(u)$ and the normal strains $\left(\varepsilon_{\mathbf{x x}}\right)$ parallel to the crack line, for a variety of nominally plane stress test specimens, do not have HRR trends identified by Hutchinson [25] and Rice and Rossengren [26]. However, for small increments of crack growth, the J- $\Delta \mathrm{a}$ curves appear to be independent of specimen geometry. For larger crack growth increments, the J- $\Delta \mathrm{a}$ data begins to display a geometry dependence. Similar results were reported by Gang, et. al. [27]. Based on scanning electron microscope (SEM) observations, Davidson et al [28], have suggested that the effective strain very close to the crack tip may be best fitted by a $\ln (r)$ form and not the power law form common to the HRR solution. Thus, considering both analytical results $[12,13]$ and experimental data, it seems clear that large amounts of stable crack growth do not occur under J-controlled conditions. These findings, and others, have prompted the search for a geometry independent crack growth criteria for large crack growth increments under large-scale plasticity.

Wells [5-7] proposed CTOD as a crack growth criterion for elastic-perfectly plastic materials experiencing large increments of crack growth under large-scale plasticity. Since the asymptotic limiting value for CTOD at the crack tip is zero, an extension of the CTOD criterion was then proposed by Rice [29] for a stationary crack; the crack-tip opening displacement $\left(\delta_{45}\right)$ was defined to be the opening displacement where $\pm 45^{\circ}$ lines drawn from the crack-tip intercept the crack faces. Shih, et. al $[10,30]$ defined CTOD as the crack-tip opening displacement at the original crack tip location. Hellman and Schwalbe [31-32] used this idea to develop $\delta_{5}-\Delta a$ resistance curves, where the $\delta_{5}$ parameter is the relative displacement of two points $5 \mathrm{~mm}$ above and below the original fatigue crack tip location.

Andersson [3] and de Koning [4] suggested that the crack-tip opening angle, CTOA, be used as a parameter characterizing the fracture process. The CTOA criterion assumes that a crack will stably tear when the angle made by the crack faces reaches a critical value. Kanninen [33-35] defined CTOA as the crack-tip opening angle at a fixed 
distance behind the current crack tip location. More recently, Demofonti and Rizzi [36] and Newman et al [37] have obtained experimental data that indicates that CTOA decreases to a constant value after a small amount of crack growth (about equal to the sheet thickness). Computational studies of stable crack growth were performed by Newman et al $[38,39]$ and Brock and Yuan [40] to assess the viability of a CTOA-based fracture criterion for numerical simulations. Both investigators determined that the use of a critical CTOA value in numerical modeling of crack growth was viable. In particular, Brock and Yuan found that specimen geometry had little effect on the CTOA- $\triangle \mathrm{a}$ curves. For fully plastic crack growth, CTOA was found to reach a stable phase when plasticity extended throughout the uncracked ligament. The stable phase was preceded by a large decrease in CTOA during the early stages of crack growth.

The objective of this study is to examine the stable tearing behavior in thin-sheet 2024-T3 aluminum alloy in $M(T)$ and $C(T)$ crack configurations. Surface CTOA values were measured by two independent techniques: far-field optical microscopy and digital image correlation. The critical CTOA criterion and an elastic-plastic, two-dimensional finite element analysis were used to simulate stable crack growth for the $\mathrm{M}(\mathrm{T})$ and $\mathrm{C}(\mathrm{T})$ configurations.

\section{Experimental Procedure}

Fracture tests were conducted on $2.3 \mathrm{~mm}$ thick 2024-T3 aluminum alloy. The yield stress and ultimate strength of the material was 345 and $490 \mathrm{MPa}$, respectively. Middle crack tension, $M(T)$, and compact tension, $C(T)$, specimens were fatigue cycled at low stress levels (to obtain a sharp crack tip), and then fractured under displacement control.

\section{Fracture Tests}

The $M(T)$ and $C(T)$ specimen configurations are shown in Figure 1. All specimens were cracked in the L-T orientation (i.e., the load was applied in the longitudinal or rolling direction and the crack was in the transverse direction or perpendicular to the longitudinal direction). The $M(T)$ specimens were fatigue cycled at a stress range of $\Delta S=34.5 \mathrm{MPa}(\mathrm{R}=0.02)$ until the total crack length was $25.4 \mathrm{~mm}$ (cracklength-to-width ratio, $2 \mathrm{a} / \mathrm{w}=0.33$ ). The $C(T)$ specimens were fatigue cycled at a load range of $\Delta \mathrm{P}=1.36 \mathrm{KN}$ until the crack length was $61 \mathrm{~mm}(\mathrm{a} / \mathrm{w}=0.4)$. The stable tearing tests were conducted using displacement control. The rate of displacement was $0.002 \mathrm{~mm} / \mathrm{sec}$. Friction grips were used for the $M(T)$ specimens and pin loading for the 
$\mathrm{C}(\mathrm{T})$ specimens. Buckling constraints were used for the $\mathrm{C}(\mathrm{T})$ tests. During each test, measurements of all or some of the following parameters were made: load, crack length, load-line displacement, local crack-tip displacements, and surface CTOA.

\section{Displacement Measurement Techniques}

Load-line displacement ( $v$ ) and local crack-tip displacements were measured for each specimen type. The load-line displacements for the $C(T)$ specimens were measured from the pin displacements. The load-line displacements for the $M(T)$ specimens and the local crack-tip displacements for both the $M(T)$ and $C(T)$ specimens were measured using the digital image correlation (DIC) technique.

The DIC setup includes (a) a video camera, (b) a $200 \mathrm{~mm}$ lens with $2 \mathrm{X}$ magnifier and several extension tubes, (c) a translation stage for positioning the video camera and following the growing crack, (d) a video monitor to view the crack tip region, (e) a video board to digitize images and (f) a microcomputer with software for controlling image acquisition and storing images. The resolution of the camera is approximately $8 \mu \mathrm{m}$ over an image area of approximately $4.1 \times 4.1 \mathrm{~mm}$. To make measurements using the DIC technique, the specimen surface was coated with a high contrast random pattern. A small region, or subset, is identified in a reference image and the relative displacement of that same subset in subsequent images is calculated. Details of the DIC technique are given in References 41-45.

The local crack-tip opening displacement $\left(\delta_{0}\right)$ is measured by calculating the relative displacements of subsets located above and below the crack plane at a distance of $0.98 \mathrm{~mm}$ to $1.02 \mathrm{~mm}$ behind the original fatigue-sharpened crack tip. The reference image was captured at zero load. Note that $\delta_{0}$ is not precisely the same as $\delta_{5}$ since $\delta_{0}$ is measured very close to the crack line and $\delta_{5}$ is measured at points $\pm 5 \mathrm{~mm}$ from the crack line. For $M(T)$ load-line displacements, the subsets are located at the centerline of the specimen. For all experiments involving $\mathrm{v}$ or $\delta_{0}$ measurements by DIC, the subset size was a square of approximately $0.12 \mathrm{~mm}$ by $0.12 \mathrm{~mm}$.

\section{CTOA Measurement Techniques}

The critical CTOA during stable tearing was measured by direct observation of the surface using an optical microscope (OM). The DIC technique was also used to measure CTOA in several tests. The OM and DIC methods were used simultaneously on opposite sides of the specimen. 
The OM setup includes (a) a long focal length microscope, (b) a video camera used to obtain images of the stably tearing crack, (c) a video recorder to store the images and (d) a PC with monitor and software to precisely control the three-dimensional positioning of the long focal length microscope and to analyze the images to obtain CTOA. The resolution of the microscope was approximately $4 \mu \mathrm{m}$ over an image area of approximately $2 \times 2 \mathrm{~mm}$. To obtain clear images of the crack using the OM, the surface of the specimen was polished to a mirror finish. Lighting of the crack region was carefully controlled so that the crack tip region had optimum contrast and clarity. Three typical images obtained using the $\mathrm{OM}$ are shown in Figure 2. In the first image, Figure 2a, a fatigue crack was grown about $0.75 \mathrm{~mm}$ under stable tearing. The second and third images, Figure $2 \mathrm{~b}$ and $2 \mathrm{c}$, contain the same crack after stable tearing of about $1.3 \mathrm{~mm}$ and $6.0 \mathrm{~mm}$, respectively.

The CTOA is measured by recalling an individual image recorded on video tape and (a) locating the crack tip, (b) locating points on both crack surfaces in the range of $0.25-1.25 \mathrm{~mm}$ behind the crack tip, (c) connecting straight lines between the crack tip and pairs of points and (d) computing the angle, $\psi$, between each pair of straight lines. The value of CTOA for a given crack length is defined to be the average of 3-10 sets of lines.

The DIC measurement of CTOA calculates the relative displacement of two subsets located above and below the crack plane at a distance of $0.25-1.25 \mathrm{~mm}$ behind the crack tip. The reference image is captured just prior to crack growth and the second image is captured during stable tearing, as shown in Figures $3 \mathrm{a}$ and $3 \mathrm{~b}$. The CTOA is calculated from the relative displacement of the two subsets and the distance from the crack tip to the subsets. Additional details on use of the DIC method for calculating CTOA are provided in Reference 46.

\section{Crack Tunneling Measurement Technique}

The extent of crack tunneling during stable tearing was measured from examination of fracture surfaces. The $\mathrm{M}(\mathrm{T})$ and $\mathrm{C}(\mathrm{T})$ specimens were fatigue cycled, as described above, to obtain a sharp crack tip. The cracks were then grown a limited amount under displacement controlled stable tearing, then fatigue cycled at $60-80 \%$ of the observed maximum load during stable tearing using a stress ratio of $R=0.8$. The different damage mechanisms (low crack growth rate fatigue and stable tearing) result in distinctly different fracture surface appearances. 


\section{Finite Element Analysis}

The elastic-plastic finite element code ZIP2D [47] was used to predict the stable tearing behavior in the $\mathrm{M}(\mathrm{T})$ and $\mathrm{C}(\mathrm{T})$ fracture tests. The program uses 3-noded, constant strain triangular elements, uses the critical CTOA criterion to extend the crack, and approximates constraint with the use of a plane strain core of elements. The elasticplastic analysis employs the initial-stress concept [48] based on incremental flow theory and small strain assumptions. A multi-linear representation of the uniaxial stress-strain curve for 2024-T3, with the data given in Table 1, was used in the analysis with a von Mises yield criterion.

\section{Finite Element Code and Meshes}

The $M(T)$ and $C(T)$ configurations had the same minimum element size $(d=$ $0.48 \mathrm{~mm}$ ) along the line of crack extension. Symmetry conditions required that only half of the $C(T)$ specimen and a quarter of the $M(T)$ specimen be modeled with one axis of symmetry along the crack line. Normally, the nodes along the crack line and ahead the crack tip are fixed, while those behind are free. This analysis used fictitious springs along the crack line to change boundary conditions associated with crack extension. The spring stiffnesses were set equal to zero for the nodes behind the crack tip and assigned extremely large values for the nodes ahead of the crack tip. Reference 37 contains the details of the elastic-plastic finite element analysis used in this work.

In all analyses, the initial crack length was set equal to the notch length. Cyclic loads were then applied and the crack was extended one element length at the maximum load of each cycle. Monotonic loading (under displacement control) was applied to simulate fracture. Crack growth by stable tearing was governed by the critical CTOA criterion.

\section{Critical CTOA Criterion}

The critical CTOA $\left(\psi_{\mathrm{c}}\right)$ criterion is equivalent to a critical CTOD $\left(\delta_{\mathrm{c}}\right)$ value at a distance behind the crack tip equal to two element lengths.

$$
\psi_{\mathrm{c}}=2 \tan ^{-1}\left(\delta_{\mathrm{c}} / 2 \mathrm{~d}\right)
$$

The crack-tip node was released and the crack advanced to the next node whenever CTOA equaled or exceeded a preset critical value $\left(\psi_{c}\right)$ during incremental loading. This process was repeated until crack growth became unstable under load control or the crack 
reached a desired length under displacement control. The critical CTOA value $\left(\psi_{c}\right)$ was determined experimentally from surface measurements made using both the OM and DIC techniques.

\section{Plane Strain Core}

A two-dimensional finite element analysis can model the structure as either plane stress or plane strain. Structures constructed of thin-sheet material exhibit predominately plane stress behavior. However, local to the crack tip, the constraint can approach plane strain conditions [14]. To approximate this local plane strain behavior, a "core" of elements above and below the crack plane were assigned plane strain behavior while all other elements were assigned plane stress behavior, as illustrated in Figure 4. The height of the plane strain core was $5 \mathrm{~mm}$, roughly twice the thickness of the specimens. This core height was determined from comparison of the calculated and experimental $\delta_{0}$ and load-line displacements.

\section{Results and Discussion}

The elastic-plastic finite element code, with the critical CTOA fracture criterion and plane strain core elements, was used to predict the stable tearing behavior for $\mathrm{M}(\mathrm{T})$ and $\mathrm{C}(\mathrm{T})$ specimens made of $2.3 \mathrm{~mm}$ thick 2024-T3 aluminum alloy. The analysis predicted the maximum load, crack extension, load-line displacement, and $\delta_{0}$ for stably tearing cracks. The critical CTOA was obtained from experimental measurements made on a stably tearing crack. Measurements of the crack front shape for the stably tearing crack were made from macroscopic observations of the fracture surfaces.

\section{CTOA Measurements}

Surface CTOA measurements of stably tearing cracks were made for $M(T)$ and $\mathrm{C}(\mathrm{T})$ specimens using the OM and DIC techniques. Results are shown in Figure 5. The CTOA behavior for the two specimen configurations was indistinguishable. During the initial stages of surface crack growth (crack extensions less than the specimen thickness), the CTOA rapidly decreased from a maximum of $12^{\circ}-22^{\circ}$ to a constant value of about $6^{\circ}$. The constant CTOA value of $6^{\circ}$, with experimental scatter of $\pm 1^{\circ}$, was maintained for all crack extensions greater than the specimen thickness $(\approx 2.3 \mathrm{~mm})$. Excellent agreement existed between the surface CTOA measured using the OM and the DIC techniques. 


\section{Crack Tunneling}

An examination of the fracture surfaces was conducted to investigate the early CTOA trends. A distinct change in the macroscopic appearance of the fracture surface occurs when the loading changes from fatigue cycling to stable tearing. A scanning electron microscope (SEM) photograph of a typical fracture surface from a $M(T)$ test with fatigue cycling followed by stable tearing is shown in Figure 6 . The fracture surface from a $C(T)$ test would appear qualitatively the same as that of the $M(T)$ test.

In the SEM photograph shown in Figure 6, the stable tearing regions appear light and the fatigue regions appear dark. The interface between the dark (fatigue) and light (stable tearing) region denotes the crack front profile before stable tearing. Also a second distinct change occurs when the loading is changed from stable tearing to high-R fatigue cycling, marking the crack front profile after stable tearing. (Note, that to the unaided eye, the fatigue region appears light and highly reflective, while the stable tearing region is dull and dark.) The interfaces between the different regions were digitized for several fracture tests.

Sequences of crack front profiles from the $M(T)$ and the $C(T)$ tests, with increasing amounts of stable crack extension, are shown in Figure 7. The crack fronts shown in Figure 7 represent trends for crack extension rather than the progression of a single crack front since each came from a different fracture test.

In the $\mathrm{M}(\mathrm{T})$ tests, the cracks grew, on average, about $0.12 \mathrm{~mm}$ more in the interior than on the surface during the initial fatigue cycling, as indicated by the first profile in Figure 7a. The second crack front showed that stable tearing crack growth began in the specimen interior. This crack front revealed no surface crack extension but the interior grew $0.5 \mathrm{~mm}$. The next four crack fronts indicate that the extent of tunneling (defined as the difference between the interior crack length and the surface crack length) increased with surface crack extension. The extent of tunneling peaked at about $1.6 \mathrm{~mm}$, after about $1 \mathrm{~mm}$ of surface crack extension and then decreased for surface crack extension up to $4 \mathrm{~mm}$. The extent of tunneling stabilized at about $0.5 \mathrm{~mm}$ for surface crack extensions greater than $4 \mathrm{~mm}$.

In the $\mathrm{C}(\mathrm{T})$ tests, the crack grew, on average, about $0.32 \mathrm{~mm}$ more in the interior than on the surface during the initial fatigue cycling, as indicated by the first profile in Figure 7b. The crack growth again began in the interior and the next two crack fronts showed a substantial amount of crack growth in the interior with only a small increase at the surfaces. The next two crack fronts indicate that the extent of tunneling increased with surface crack extension. The extent of tunneling peaked at about $2.8 \mathrm{~mm}$, after about 
$2 \mathrm{~mm}$ of surface crack extension, and then decreased for surface crack extensions greater than $4 \mathrm{~mm}$. The extent of tunneling stabilized at about $1 \mathrm{~mm}$ for larger surface crack extensions.

The extent of tunneling that developed during stable tearing is shown in Figure 8, where the normalized extent of tunneling (the difference between the interior crack length and the surface crack length $\left(a_{i}-a_{s}\right)$ divided by the thickness (B)) is plotted as a function of surface crack extension $\left(\Delta \mathrm{a}_{\mathrm{s}}\right)$. To illustrate the trends in the crack tunneling behavior, curves were faired through the data shown in Figure 8. The tunneling in the $M(T)$ tests, peaked at about $\left(a_{\mathrm{i}}-\mathrm{a}_{\mathrm{s}}\right) / \mathrm{B}=0.7$ (70\% of the specimen thickness) after about $1 \mathrm{~mm}$ of surface crack growth and dropped off to about 0.2 for crack extensions greater than $1 \mathrm{~mm}$. The tunneling in the $C(T)$ tests peaked at about $\left(a_{i}-a_{s}\right) / B=1.2(120 \%$ of the specimen thickness) after about $2 \mathrm{~mm}$ of surface crack growth and dropped off to about 0.3 for longer crack extensions greater than $2 \mathrm{~mm}$.

As shown in Figures 7 and 8, the tunneling differences between $M(T)$ and $C(T)$ specimens are only significant for crack extensions less than twice the thickness $\left(\Delta \mathrm{a}_{\mathrm{s}}<4.6 \mathrm{~mm}\right)$. This is consistent with the higher initial constraint present in a $\mathrm{C}(\mathrm{T})$ specimen [16]. During crack growth, the constraint differences between $M(T)$ and $C(T)$ specimens will decrease as yielding progresses through the thickness and throughout the remaining ligament.

In addition to crack tunneling, the crack front transitions from flat-to-slant fracture. The transition occurred over a distance roughly equal to two thicknesses $(\Delta \mathrm{a}<$ $4.6 \mathrm{~mm})$ in the $\mathrm{M}(\mathrm{T})$ specimens. The transition distance in the $\mathrm{C}(\mathrm{T})$ was specimens slightly longer than in the $M(T)$ specimens.

\section{Crack Extension and Displacement Measurements and Calculations}

Thirteen identical $M(T)$ fracture tests and six identical $C(T)$ fracture tests were conducted. The $\mathrm{M}(\mathrm{T})$ fracture tests had a $2.5 \%$ variation in the maximum applied stress, while the $C(T)$ fracture tests had a $8.3 \%$ variation in the maximum applied load, as summarized in Tables 2 and 3.

The critical CTOA fracture criterion and a two-dimensional, elastic-plastic finite element analysis were used to calculate the maximum applied load, crack extension behavior, $\delta_{0}$ and load-line displacements. The stabilized surface CTOA value of $6^{\circ}$, as measured by the OM and DIC methods, was used as the critical angle. The size of the plane strain core used in the finite element analysis was established by finding the size 
that produced the best agreement between calculated and measured load-line and $\boldsymbol{\delta}_{\mathbf{0}}$ displacements.

The load-line and $\delta_{0}$ displacement behavior for two $C(T)$ specimens are shown in Figures 9 and 10, respectively. The plane stress finite element calculation overpredicted the experimentally measured maximum applied load by about $15 \%$ and overpedicted the displacements by as much as $40 \%$. The addition of a plane strain core of elements (halfheight of $2.5 \mathrm{~mm}$ ) decreased the calculated maximum applied load to a value equal to the average value of 6 tests and resulted in a very good agreement between the calculated and measured displacements, as shown in Figures 9 and 10.

The load-line and $\delta_{0}$ displacement behavior for the $M(T)$ specimens are shown in Figures 11 and 12, respectively. The plane stress finite element calculation slightly underpredicted the experimentally measured maximum applied load and overpredicted the $\delta_{0}$ displacement. The addition of a plane strain core of elements (half height of $2.5 \mathrm{~mm}$ ) resulted in a very good agreement between the calculated and measured loaddisplacement behavior, as shown in Figures 11 and 12.

Figure 13 shows a comparison of the calculated and measured crack extension behavior of four identical $\mathrm{C}(\mathrm{T})$ fracture tests. The plane stress analysis over predicted the maximum applied load by about $15 \%$. The plane strain core analysis agreed well with the measured load-crack extension behavior. At peak load, the plane strain core calculation falls in the middle of the experimental scatter of the $C(T)$ measurements. After peak load, the crack extension behavior calculated using the plane strain core has the same shape as the experimental measurements, but falls along the top of the scatter band of the data.

Figure 14 shows a comparison of the calculated and measured crack extension behavior for thirteen identical $\mathrm{M}(\mathrm{T})$ fracture tests. Both the plane stress and plane strain core analyses agree well with the experimental measurements. The analyses tend to slightly overpredict the initial crack extension $(\Delta \mathrm{a}<2 \mathrm{~mm})$. However, the experimental measurements were made from surface observations and significant crack tunneling was shown to occur in this region. The analyses accurately describe the crack extension behavior beyond the peak stress.

The calculation of load-displacement and load-crack extension behavior for the $\mathrm{C}(\mathrm{T})$ specimen was strongly influenced by the state of stress along the crack plane. Using the experimentally measured critical CTOA value of $6^{\circ}$, the plane stress analysis overcalculated both load and local displacements associated with stable tearing. The analysis of the $M(T)$ specimen indicated only a minor influence of the state of stress on the calculated load and local displacements. 


\section{Concluding Remarks}

The stable tearing behavior of thin sheets of 2024-T3 aluminum alloy was investigated for middle crack tension, $M(T)$, and compact tension, $C(T)$, specimens. Results of this study are as follows:

(1) The measured CTOA behavior for the $M(T)$ and $C(T)$ specimens was nearly identical. Both had high CTOA values for initial crack growth $(\Delta \mathrm{a}<2.3 \mathrm{~mm})$ and stabilized at a value of about $6^{\circ}$ for crack extensions greater than about $2.3 \mathrm{~mm}$, a length approximately equal to the specimen thickness.

(2) Both the $M(T)$ and $C(T)$ specimens exhibited substantial crack tunneling during the early portion of stable tearing $(\Delta \mathrm{a}<2.3 \mathrm{~mm})$. The maximum tunneling of the $C(T)$ specimens was almost twice that of the $M(T)$ specimens. This increase is consistent with the increased constraint present in $\mathrm{C}(\mathrm{T})$ specimens during the initial crack growth.

(3) A two-dimensional, elastic-plastic finite element model was used to calculate the maximum applied load and local displacements for $M(T)$ and $C(T)$ fracture tests. The finite element model used a constant CTOA crack growth criterion (critical CTOA of $6^{\circ}$ ) and a plane strain core of elements ( $5 \mathrm{~mm}$ high) for both specimen configurations. For the analyses with the plane strain core, the calculated maximum loads were within $2 \%$ for the $M(T)$ and $4 \%$ for the $C(T)$ fracture tests, and the local displacement predictions agreed with the magnitude and trends of the experimental measurements.

(4) The use of a plane strain core of elements along the crack plane was essential to accurately model the load-crack extension and load-local displacement behavior in both the $M(T)$ and $C(T)$ specimens. The plane strain core had a much greater influence on the behavior of the $C(T)$ than on the $M(T)$ specimen.

(5) Despite significant three-dimensional effects, such as crack tunneling and the flatto-slant transition, the two-dimensional finite element analysis was successful in simulating stable tearing behavior.

\section{References}

1. Harris, C. E., "NASA Aircraft Structural Integrity Program," NASA TM102637, April 1990.

2 Kanninen, M. F., "The Analysis of Stable Crack Growth in Type 304 Stainless Steel," Proceedings of the International Conference of Fracture, 1980, pp. 17591768.

3 Andersson, H., "Finite Element Representation of Stable Crack Growth," Journal of Mechanics and Physics of Solids, Vol. 21, 1973, pp. 337-356.

4 de Koning, A. U., "A Contribution to the Analysis of Quasi Static Crack Growth in Steel Materials," Fracture 1977, Vol. 3, 1977, pp. 25-31. 
5 Wells, A. A.," Unstable Crack Propagation in Metals: Cleavage and Fast Fracture," Proceedings of the Cranfield Crack Propagation Symposium, Vol. 1, 1961, pp. 210-230.

6 Wells, A. A., "Application of Fracture Mechanics at and Beyond General Yielding," British Welding Journal, Vol. 10, No. 11, 1963, pp. 563-570.

7 Wells, A. A., "Notched Bar Tests, Fracture Mechanics and Brittle Strengths of Welded Structures," British Welding Journal, Vol. 12, No. 1, 1965, pp. 2-13.

8 Broberg, K. B., "On Stable Crack Growth," Journal of the Mechanics and Physics of Solids, Vol. 23, 1975, pp. 215-237.

9 Orowan, E., "Fracture and Strength of Solids," Report of Progress in Physics, Vol. 12, 1949, Physical Society of London.

10 Shih, C. F., de Lorenzi, H. G. and Andrews W. R., "Studies on Crack Initiation and Stable Crack Growth," Elastic-Plastic Fracture, ASTM STP 668, 1979, pp. $65-120$.

11 Shih, C. F., Dean, R. H., and German M. D., "On J-Controlled Crack Growth: Evidence, Requirements and Applications," General Electric Co. T13 Report Schenectady, New York, 1981.

12 Hutchinson, J. W., and Paris, P. C., "The Theory of Stability Analysis of JControlled Crack Growth," Elastic-Plastic Fracture, ASTM STP 668, 1979, pp. 37-64.

13 McMeeking, R. M., and Park, D. M., "On Criteria for J-Dominance of Crack Tip Fields in Large Scale Yielding," Elastic-Plastic Fracture, ASTM STP 668, 1979, pp. 175-194.

14 Hom, C. L. and McMeeking, R. M., "Large Crack-Tip Opening in Thin, ElasticPlastic Sheets," International Journal of Fracture, Vol. 45, 1980, pp. 103-122.

15 Newman, J. C., Jr., Bigelow, C. A., and Shivakumar, K. N., "ThreeDimensional Elastic-Plastic Finite-Element Analysis of Constraint Variations in Cracked Bodies," NASA TM-107704, 1993.

16 Leevers, P. S. and Radon, J. C., "Inherent Stress Biaxiality in Various Specimen Geometries," International Journal of Fracture, Vol. 19, 1985, pp. 311-325.

17 Yang, S., Chaw, Y. J., and Sutton, M. A., "Higher Order Asymptotic Crack Tip Stress Fields in Power Law Hardening Materials," Engineering Fracture Mechanics, Vol. 45, No. 1, 1993, pp. 1-20.

18 Kang, B. S.-J. and Kobayashi, A. S., "J-Estimation Procedure based on Moiré interferometry data," ASME Journal for Pressure Vessel Technology, Vol. 110, 1988, pp. 291-300.

19 Kang, B. S.-J. and Kobayashi, A. S., "Stable Crack Growth in Aluminum Tensile Specimens," Experimental Mechanics, Vol. 27, 1987, pp. 234-245. 
20 Dadkhah, M. S. and Kobayashi, A. S., "HRR Field of a Moving Crack, an Experimental Analysis," Engineering Fracture Mechanics, Vol. 34, 1989, pp. 253-262.

21 Dadkhah, M. S. and Kobayashi, A. S., "Further Studies in the HRR Field of a Moving Crack, an Experimental Analysis," Journal of Plasticity, Vol. 6, 1990, pp. 635-650.

22 Kobayashi, A. S., Dadkhah, M. S. and Kang, B. S.-J. "J-Integral and HRR Field of a Stably Growing Crack, an Experimental Analysis," UWA/DME/TR-90/65, Office of Naval Research, April 1990.

23 Drinnon, R. H. and Kobayashi, A. S., "J-Integral and HRR Field Associated with Large Crack Extension," Engineering Fracture Mechanics, Vol. 41, No. 5, 1992, pp. 684-694.

24 Dadkhah, M. S., Kobayashi, A. S., and Morris, W. L., "Crack Tip Displacement Fields and $\mathrm{J}_{\mathrm{r}}$-Curves for Four Aluminum Alloys," Fracture Mechanics: Twenty Second Symposium, ASTM STP 1131, Vol. II, 1992, pp. 135-153.

25 Hutchinson, J. W., "Plastic Stress and Strain Fields at a Crack Tip," Journal of the Mechanics and Physics of Solids, Vol. 16, 1968, pp. 13-31.

26 Rice, J. R. and Rossengren, G. F., "Plane Strain Deformation Near a Crack Tip in a Power-Hardening Material," Journal of the Mechanics and Physics of Solids, Vol. 16, 1968, pp. 1-12.

27 Gang, H., Sutton, M. A., Chao, Y. J. and Lyons, J. S., "Ductile Crack Blunting, Initiation and Crack Growth Analysis of 304 Stainless Steel Specimens by Computer Vision," Proceedings of Spring SEM Conference, 1993.

28 Davidson, D. C., "The Distribution of Strain with Crack Tip Plastic Zones," Engineering Fracture Mechanics, Vol. 25, No. 1, 1986, pp. 123-132.

29 Rice, J. R., and Sorensen, E. P., "Continuing Crack-Tip Deformation and Fracture for Plane strain Crack Growth in Elastic-Plastic Solids," Journal of Mechanics and Physics of Solids, Vol. 26, 1978, pp. 163-186.

30 Shih, C. F.," Studies on Crack Initiation and stable Crack Growth," Elastic Plastic Fracture, ASTM STP 668, 1979, pp. 65-120.

31 Hellman, D. and Schwalbe, K.-H., "Geometry and Size Effects on J-R and d-R Curves Under Plane Stress Conditions," Fracture Mechanics: Fifteenth Symposium, ASTM STP 833, 1984, pp. 577-605.

32 Hellman, D. and Schwalbe, K.-H., "On the Experimental Determination of CTOD Based R-Curves," Proceedings of the Conference on Crack Tip Opening Displacement in Elastic-Plastic Fracture Mechanics, 1986, pp. 115-132.

33 Kanninen, M. F., "The Analysis of Stable Crack Growth in Type 304 Stainless Steel," Proceedings of the International Conference of Fracture, 1980, pp. 17591768 . 
34 Kanninen, M. F., Popelar, C. H., and Broek, D. Nuclear Engineering and Design, Vol., 67, 1981, pp. 27-55.

35 Kanninen, M. F., "Advanced Fracture Mechanics," Oxford University Press, 1985 , pp. 367-387.

36 Demofonti, G. and Rizzi, L., "Experimental Evaluation of CTOA in Controlling Unstable Ductile Fracture Propagation," ESIS Pub. 9, 1991, pp. 693-703.

37 Newman, J. C., Jr., Dawicke, D. S., and Bigelow, C. A., "Finite-Element Analysis and Measurement of CTOA During Stable Tearing in a Thin-Sheet Aluminum Alloy," Proceedings from the International Workshop on Structural Integrity of Aging Airplanes, April 1992, pp. 167-186.

38 Newman, J. C., Jr. "An Elastic-Plastic Finite Element Analysis of Crack Initiation, Stable Crack Growth, and Instability," Fracture Mechanics: Fifteenth Symposium, ASTM STP 833, 1984, pp. 93-117.

39 Newman, J. C., Jr., Shivakumar, K. N., and McCabe, D. E., "Finite Element Fracture Simulation of A533B Steel Sheet Specimens", ESIS Pub. 9, 1991, pp. 117-126.

40 Brocks, W. and Yuan, H. "Numerical Studies on Stable Crack Growth", ESIS Pub. 9, 1991, pp. 19-33.

41 Sutton, M. A., Bruck, H. A., Chae, T. L., and Turner, J. L., "Experimental Investigations of Three-Dimensional Effects Near a Crack Tip Using Computer Vision," International Journal of Fracture, Vol. 53, 1991, pp. 201-228.

42 Sutton, M. A., Bruck, H. A., and McNeill, S. R., "Determination of Deformations Using Digital Correlation with the Newton Raphson Method for Partial Differential Correction," Experimental Mechanics, Vol. 29, No. 3, 1989 , pp. 261-267.

43 Sutton, M. A., Turner, J. L., Chae, T. L., and Bruck, H. A., "Development of a Computer Vision Methodology for the Analysis of Surface Deformation in Magnified Image," MICOM 90, ASTM STP 1094, 1990, pp. 109-132.

44 Sutton, M. A., Turner, J. L., Bruck, H. A., and Chae, T. L., "Full-Field Representation of the Discretely Sampled Surface Deformation for Displacement and Strain Analysis," Experimental Mechanics, Vol. 31, No. 2, 1991, pp. 168-177.

45 Sutton, M. A. and McNeill, S. R., "The Effects of Subpixel Image Restoration on Digital Correlation Error Estimates," Optical Engineering, Vol. 27, No. 3, 1988, pp. 163-175.

46 Dawicke, D. S., Sutton, M. A., "Crack-Tip Opening Angle Measurements and Crack Tunneling Under Stable Tearing in Thin Sheet 2024-T3 Aluminum Alloy," Submitted to Experimental Mechanics, June 1993.

47 Newman, J. C., Jr., "Finite-Element Analysis of Fatigue Crack Propagation-Including the Effects of Crack Closure," Ph.D. Thesis, VPI \& State University, Blacksburg, VA, May 1974. 
48 Zienkiewicz, O. C., Valliappan, S., and King, I. P., "Elasto-Plastic Solutions of Engineering Problems, Initial Stress, Finite Element Approach," International Journal of Numerical Methods in Engineering, Vol. 1, 1969, pp. 75-100. 
Table 1

Multi-Linear Representation of the Uniaxial Stress-Strain Curve for 2024-T3

\begin{tabular}{|c|l|c|}
\hline $\begin{array}{c}\sigma \\
(\mathrm{MPa})\end{array}$ & \multicolumn{1}{|c|}{$\varepsilon$} \\
\hline 345 & 0.00483 & \multirow{3}{*}{$\mathrm{E}=71,400 \mathrm{MPa}$} \\
\hline 390 & 0.015 & \multirow{2}{*}{$v=0.3$} \\
\hline 430 & 0.04 & \\
\hline 470 & 0.1 & \\
\hline 490 & 0.16 & \\
\hline 490 & 0.2 & \\
\hline
\end{tabular}

Table 2

Summary of $13 \mathrm{M}(\mathrm{T})$ Fracture Tests

\begin{tabular}{|c|c|}
\hline & $\begin{array}{c}\text { Maximum Applied } \\
\text { Load } \\
\text { (KN) }\end{array}$ \\
\hline Highest of 13 tests & 42.0 \\
\hline Average of 13 tests & 41.5 \\
\hline Lowest of 13 tests & 40.9 \\
\hline $\begin{array}{c}\text { Calculated } \\
\text { (Plane Strain Core) }\end{array}$ & 41.8 \\
\hline $\begin{array}{c}\text { Calculated } \\
\text { (Plane Stress) }\end{array}$ & 40.2 \\
\hline
\end{tabular}

Table 3

Summary of $6 \mathrm{C}(\mathrm{T})$ Fracture Tests

\begin{tabular}{|c|c|}
\hline & $\begin{array}{c}\text { Maximum Applied } \\
\text { Load } \\
\text { (KN) }\end{array}$ \\
\hline Highest of 6 tests & 10.4 \\
\hline Average of 6 tests & 10.1 \\
\hline Lowest of 6 tests & 9.6 \\
\hline $\begin{array}{c}\text { Calculated } \\
\text { (Plane Strain Core) }\end{array}$ & 10.1 \\
\hline $\begin{array}{c}\text { Calculated } \\
\text { (Plane Stress) }\end{array}$ & 11.7 \\
\hline
\end{tabular}




\section{C(T) Specimen}

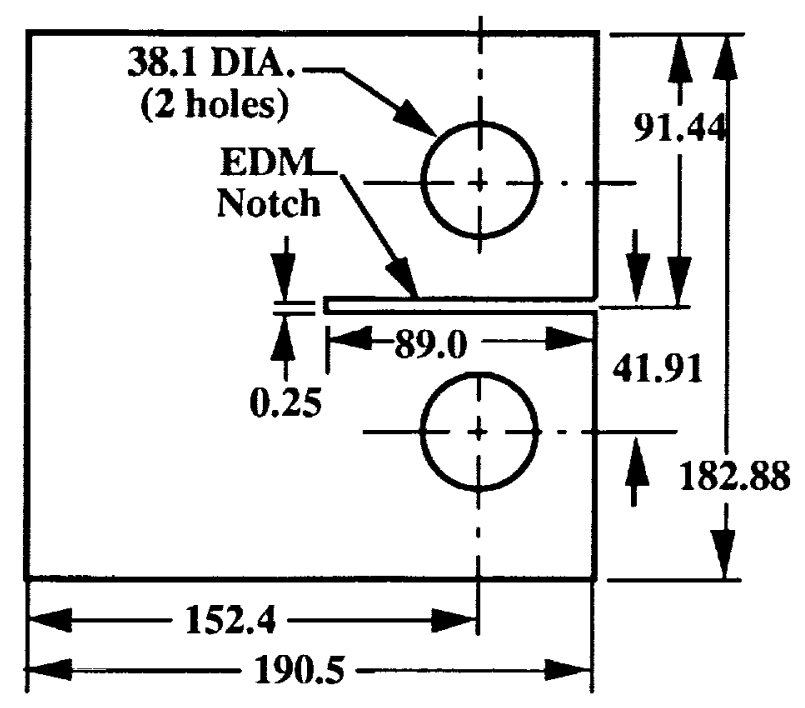

Note: All dimensions in $\mathbf{~ m m}$
M(T) Specimen

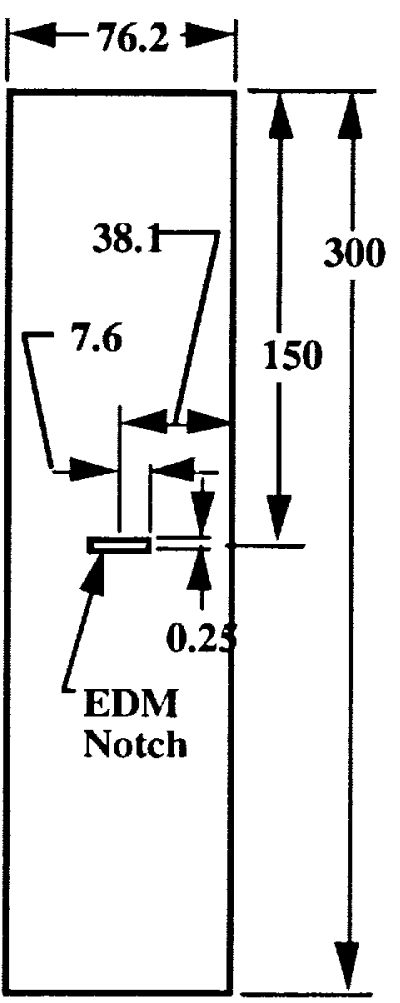

Figure 1. $\quad M(T)$ and $C(T)$ specimen configurations. 


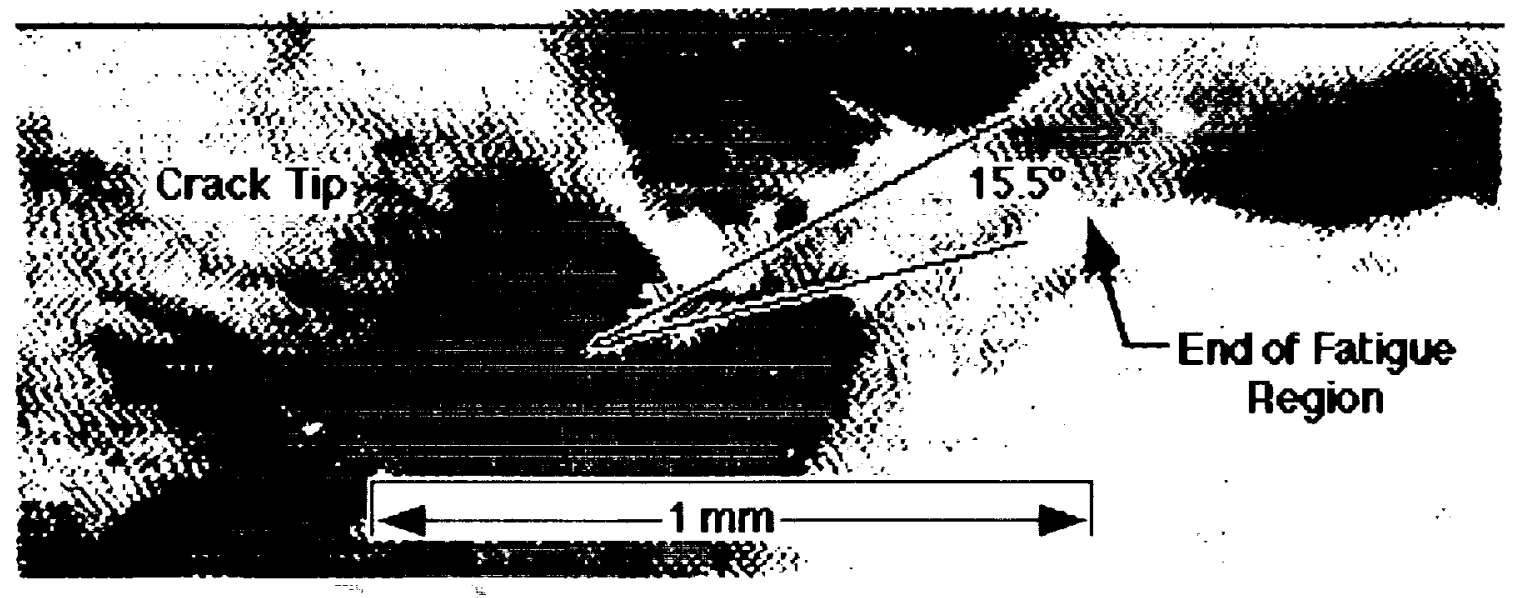

a. OM image after about $0.75 \mathrm{~mm}$ of stable tearing

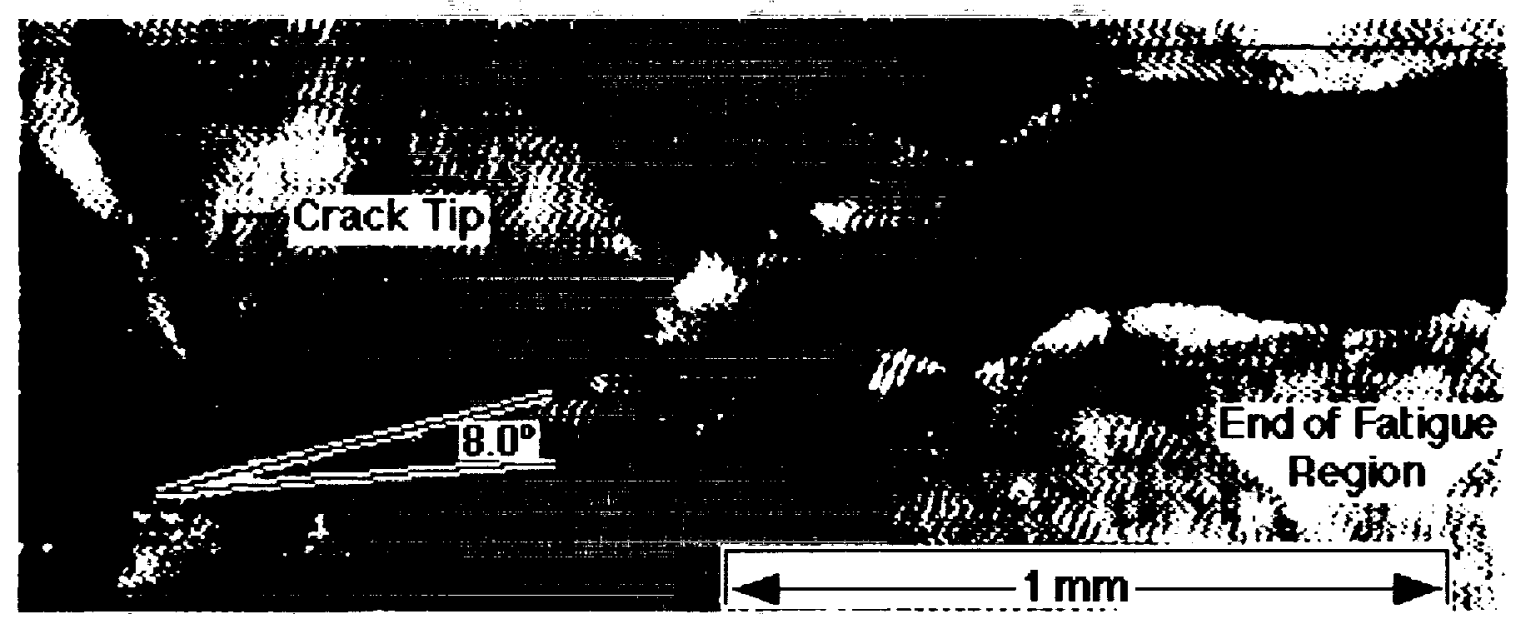

b. OM image after about $1.3 \mathrm{~mm}$ of stable laaring

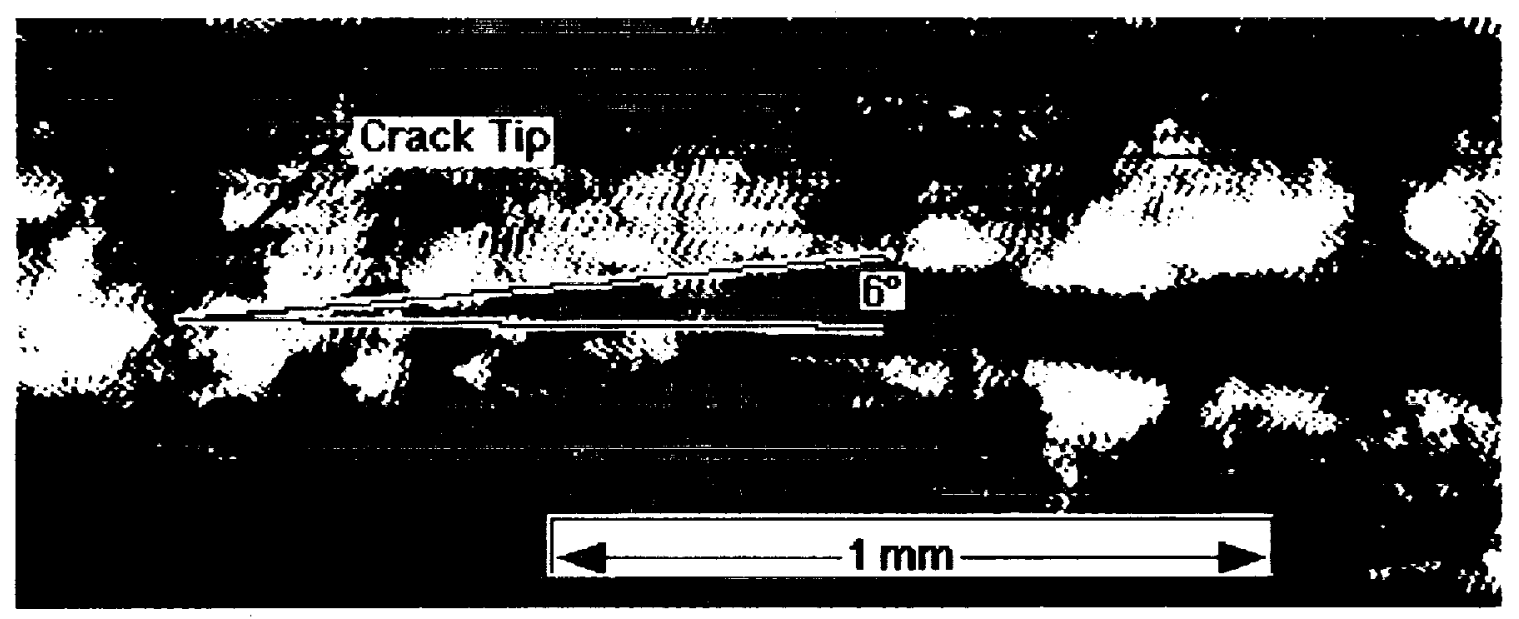

c. OM image after about $6 \mathrm{~mm}$ of stable tearing

Figure 2

Typical OM images and CTOA measurements for stable tearing cracks in $2.3 \mathrm{~mm}$ thick $2(124-\mathrm{T} 3$ aluminum alloy. 


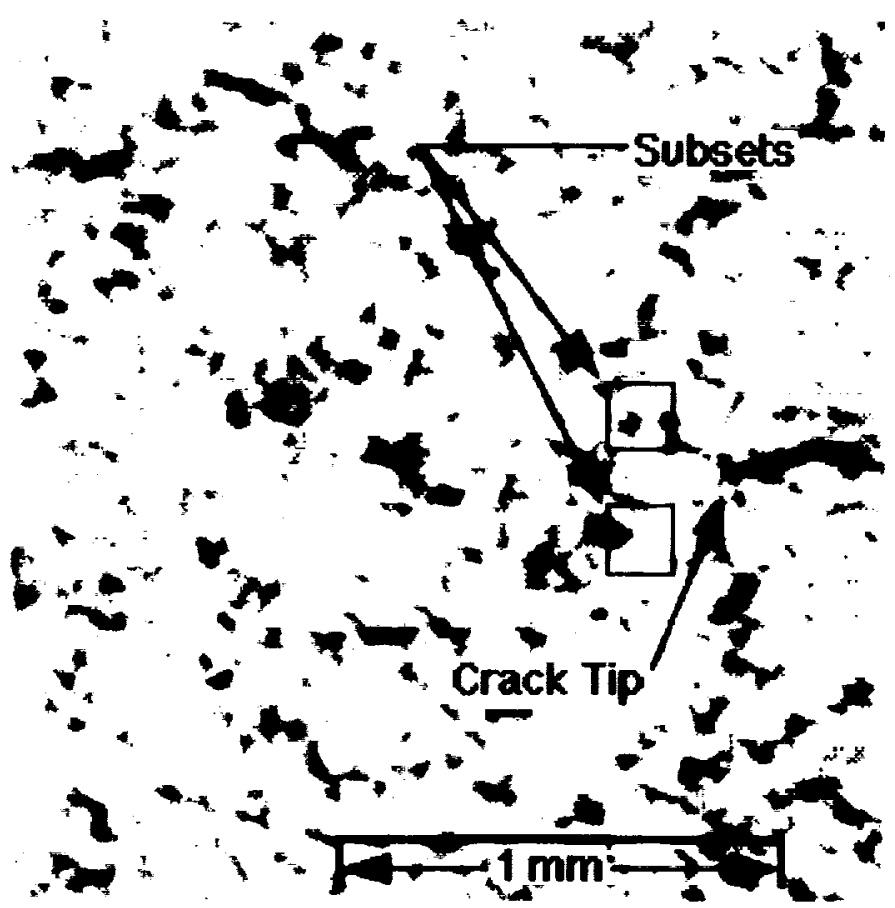

a. Before crack extension

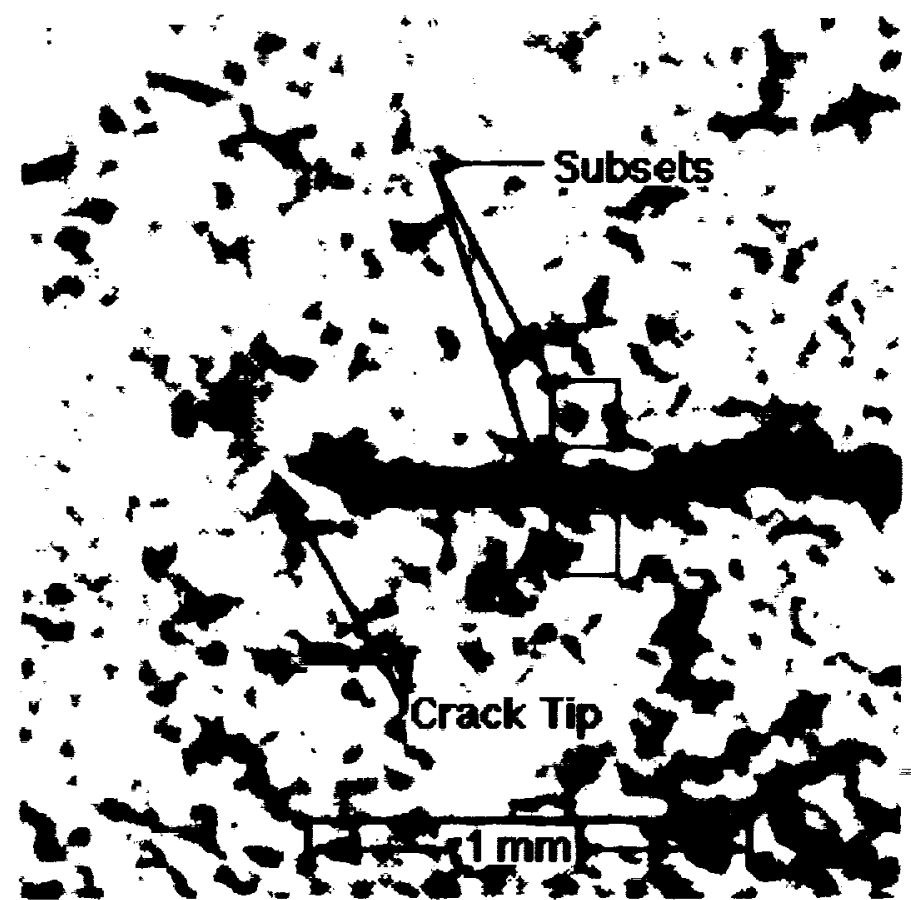

b. During crack extension

Figure 3 Images of a stably tearing crack obtained from the DIC method and the subsets used to obtain the CTOA. 


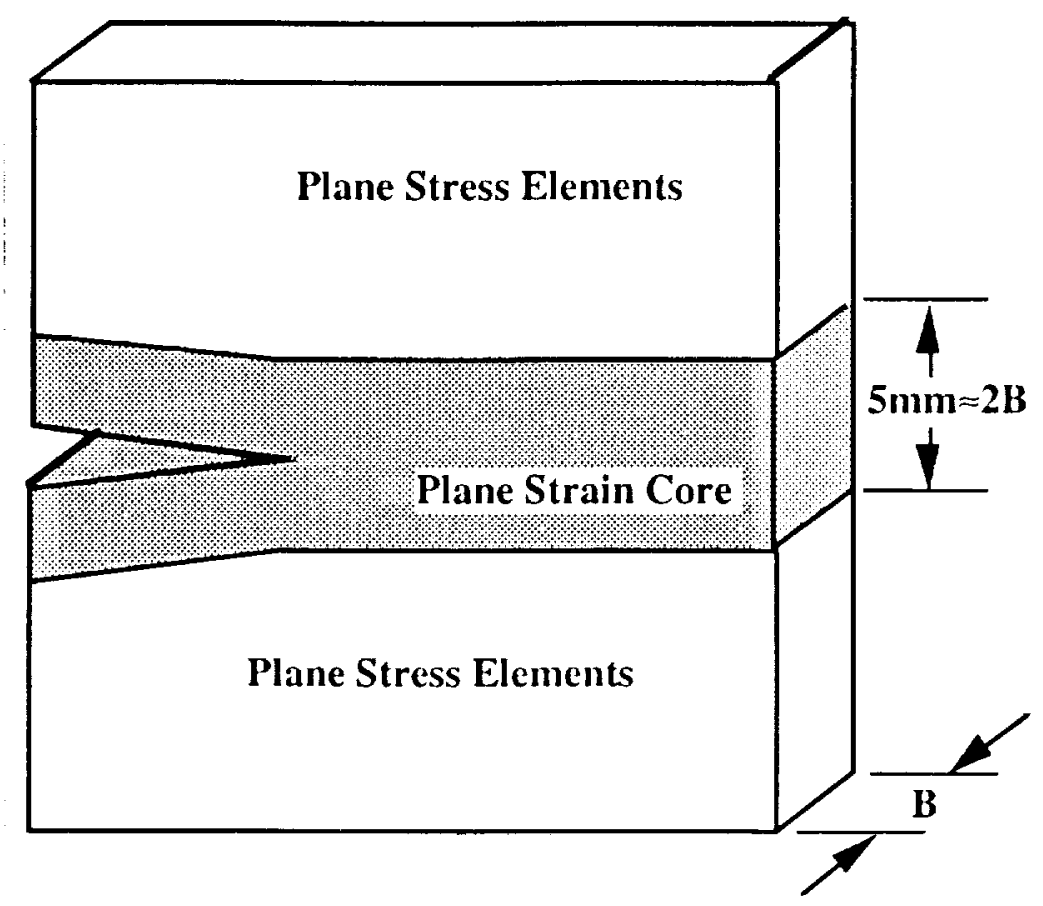

Figure 4 Schematic of the plane strain core. 


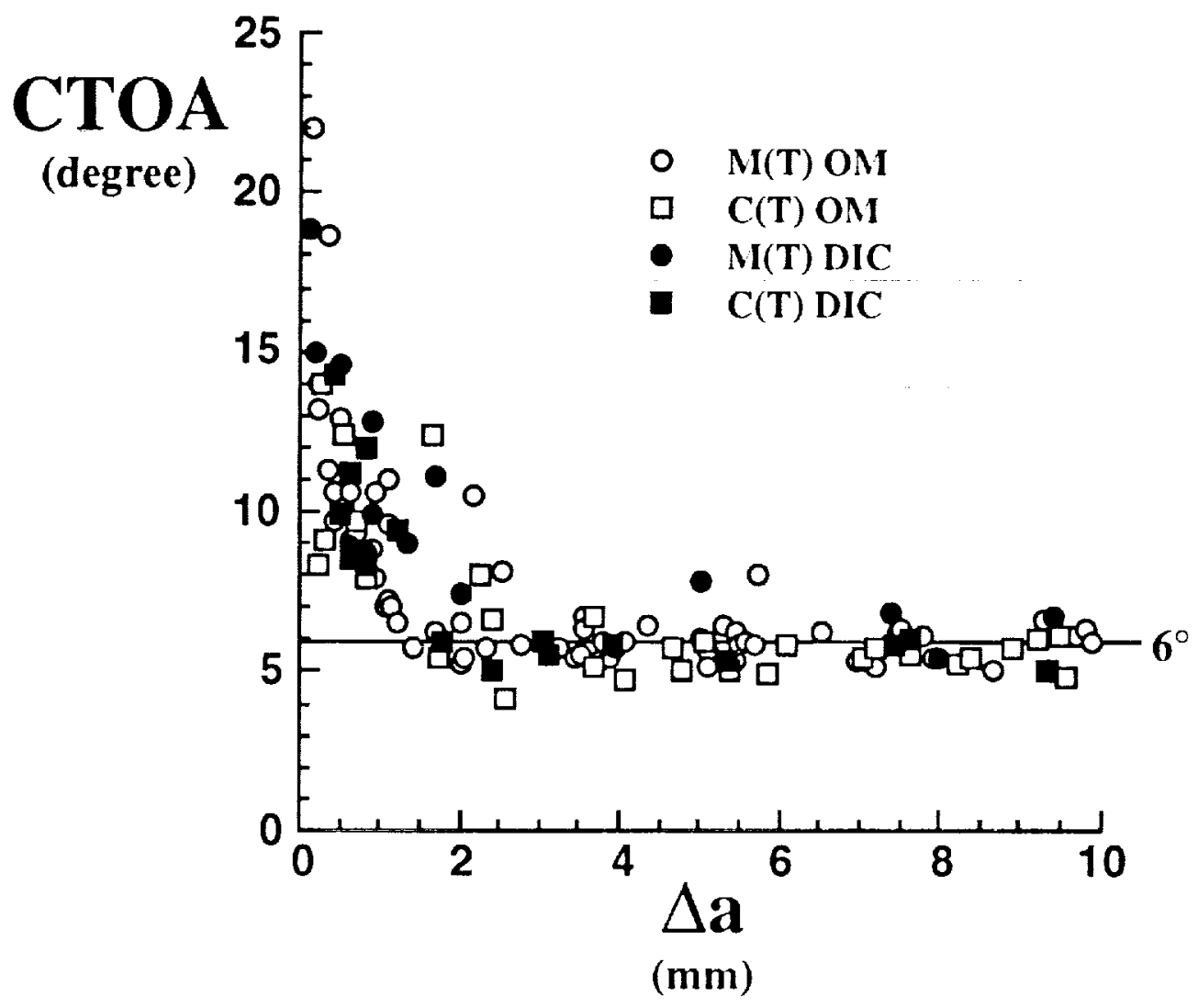

Figure 5 Surface crack-tip opening angles (CTOA) measured using the optical microscopy (OM) and digital image correlation (DIC) methods for the $\mathrm{M}(\mathrm{T})$ and $\mathrm{C}(\mathrm{T})$ specimens. 


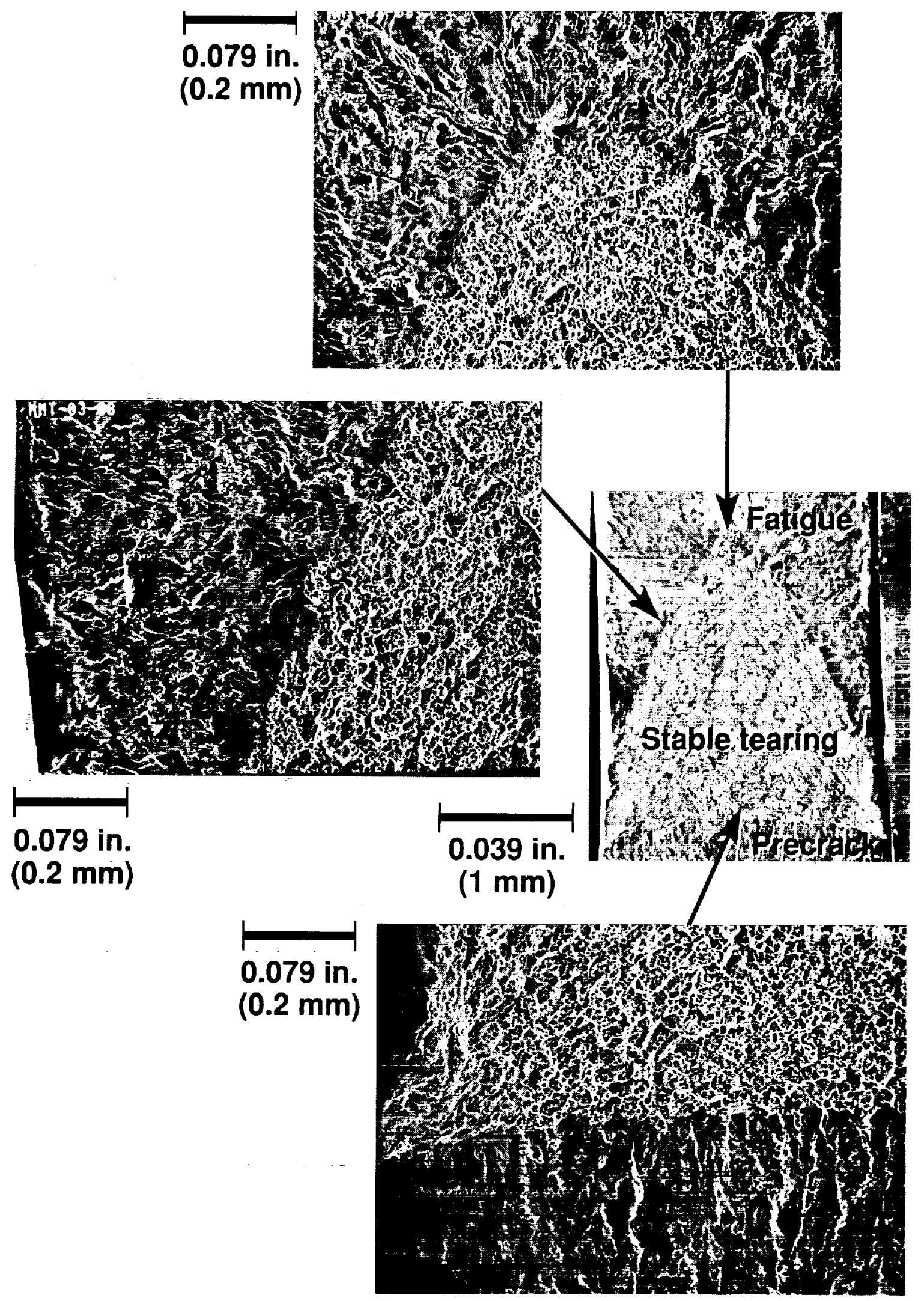

Figure 6. Scanning electron microscope photographs of the fracture surface of a $M(T)$ specimen showing the different appearances of the fatigue crack growth and stable tearing regions. 


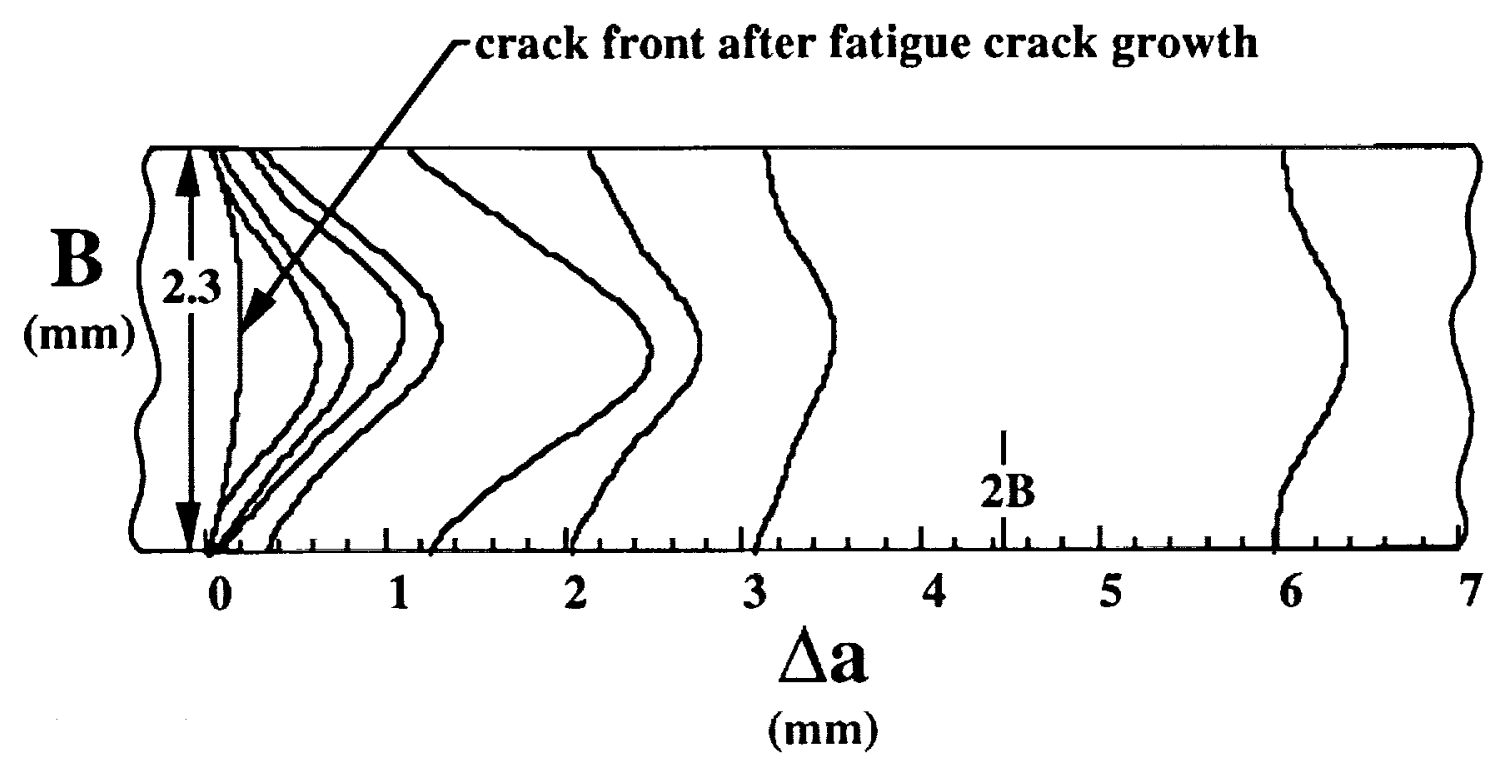

a. Crack front profiles from $M(T)$ tests

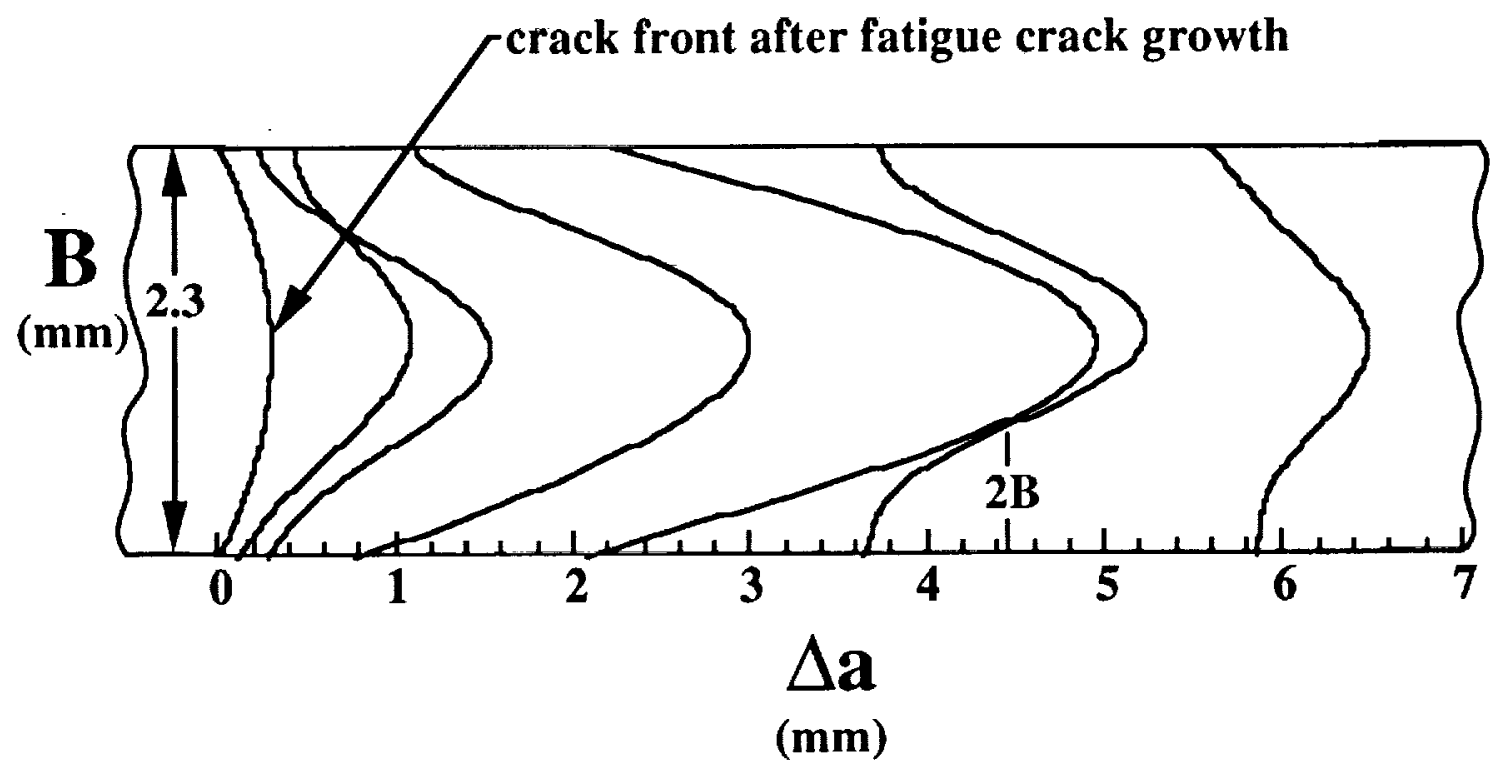

b. Crack front profiles from $\mathrm{C}(\mathrm{T})$ tests

Figure 7. Crack front profiles after stable tearing for the $M(T)$ and $C(T)$ fracture tests. 


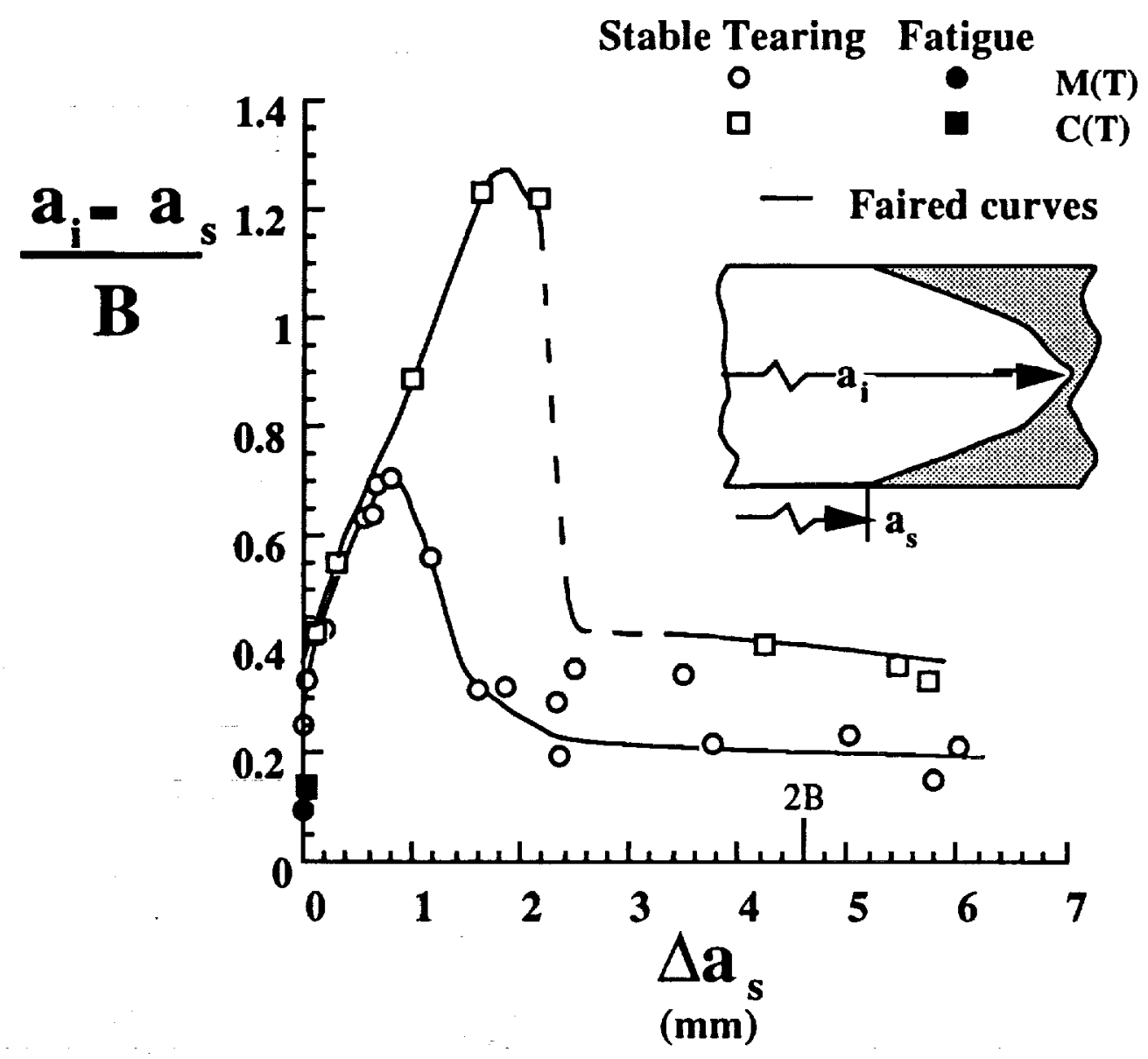

Figure 8. The extent of crack tunneling for the $M(T)$ and $C(T)$ fracture tests. 


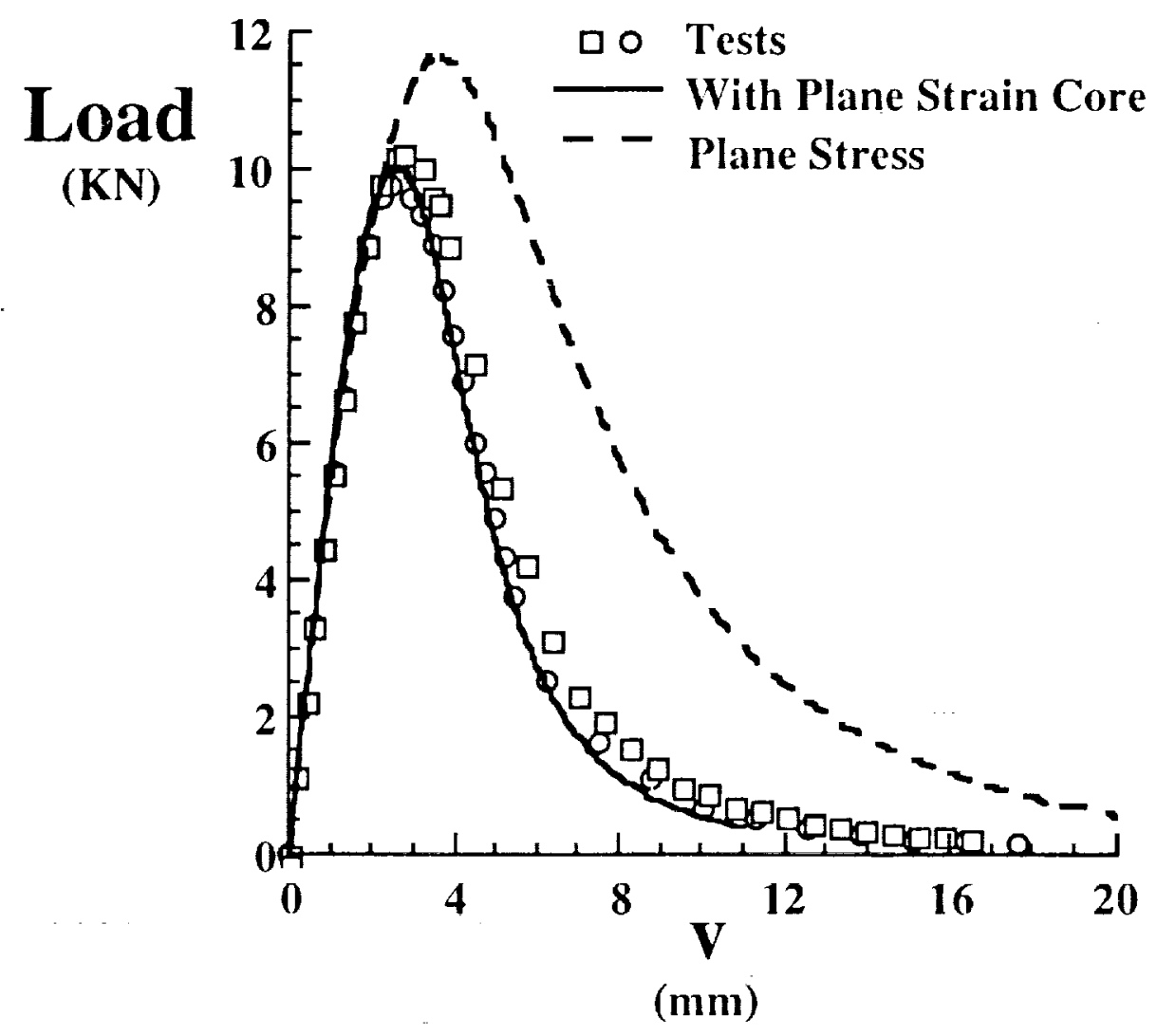

Figure 9. The experimentally measured load-line displacement as a function of the remote load and the two-dimensional, finite element analysis calculation for two $C(T)$ fracture tests. 


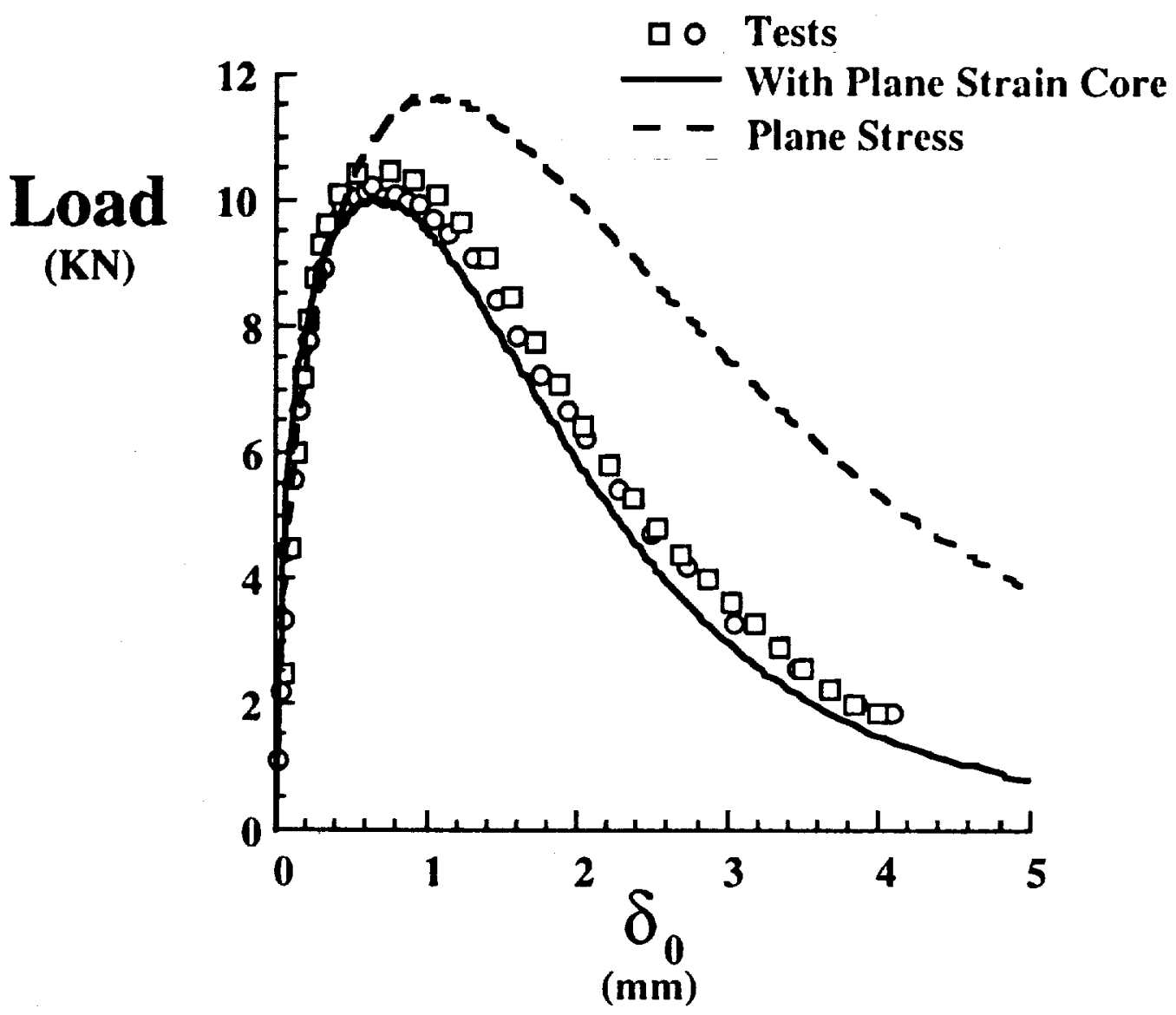

Figure 10. The experimentally measured $\delta_{0}$ displacement as a function of the remote load and the two-dimensional, linite element analysis calculation for two $\mathrm{C}(\mathrm{T})$ fracture test. 


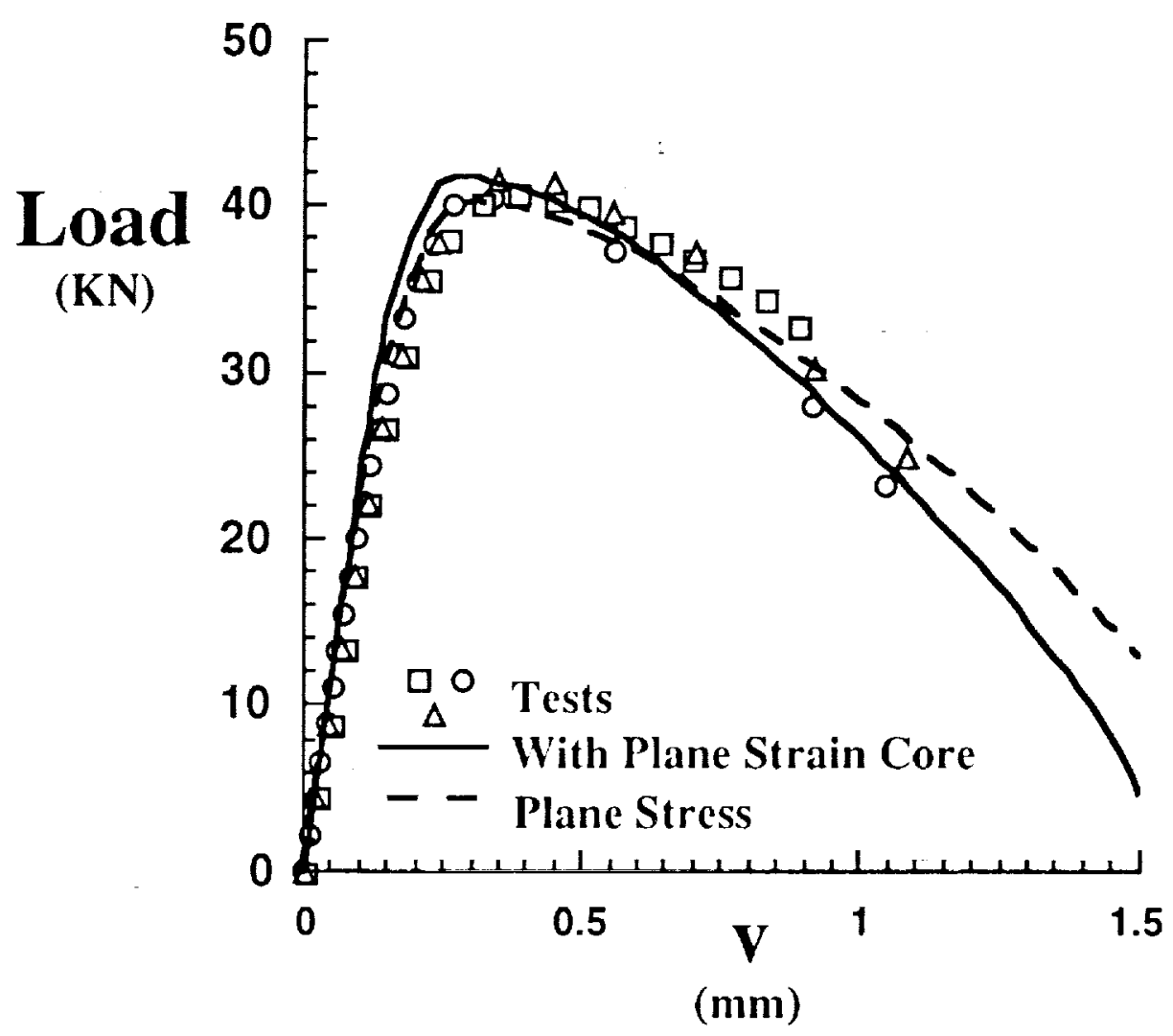

Figure 11. The experimentally measured load-line displacement as a function of the remote load and the two-dimensional, finite element analysis calculation for three $M(T)$ lracture tests. 


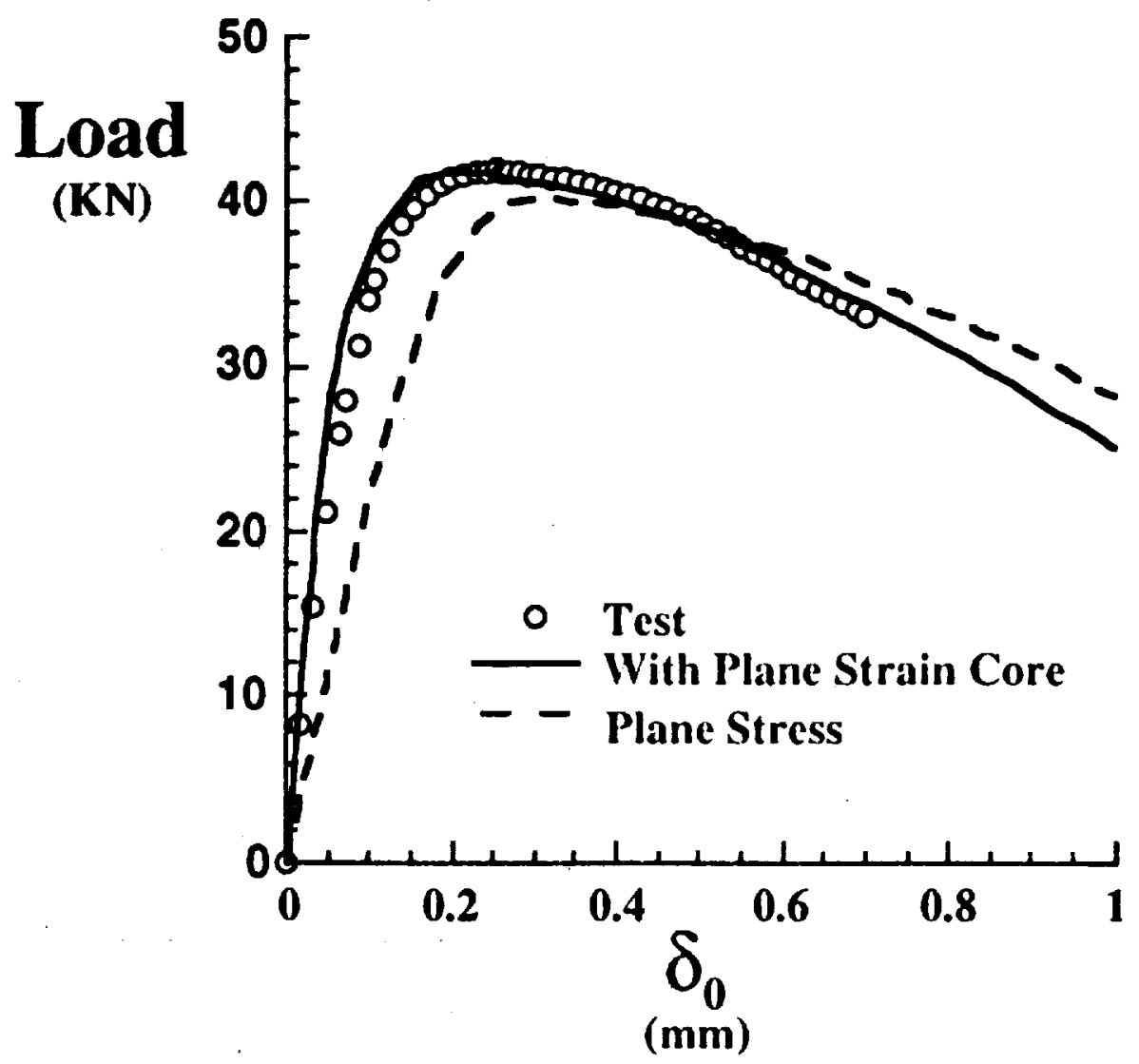

Figure 12. The experimentally measured $\delta_{0}$ displacement as a lunction of the remote load and the two-dimensional, linite elernent analysis calculation for a $\mathrm{M}(\mathrm{T})$ fracture test. 


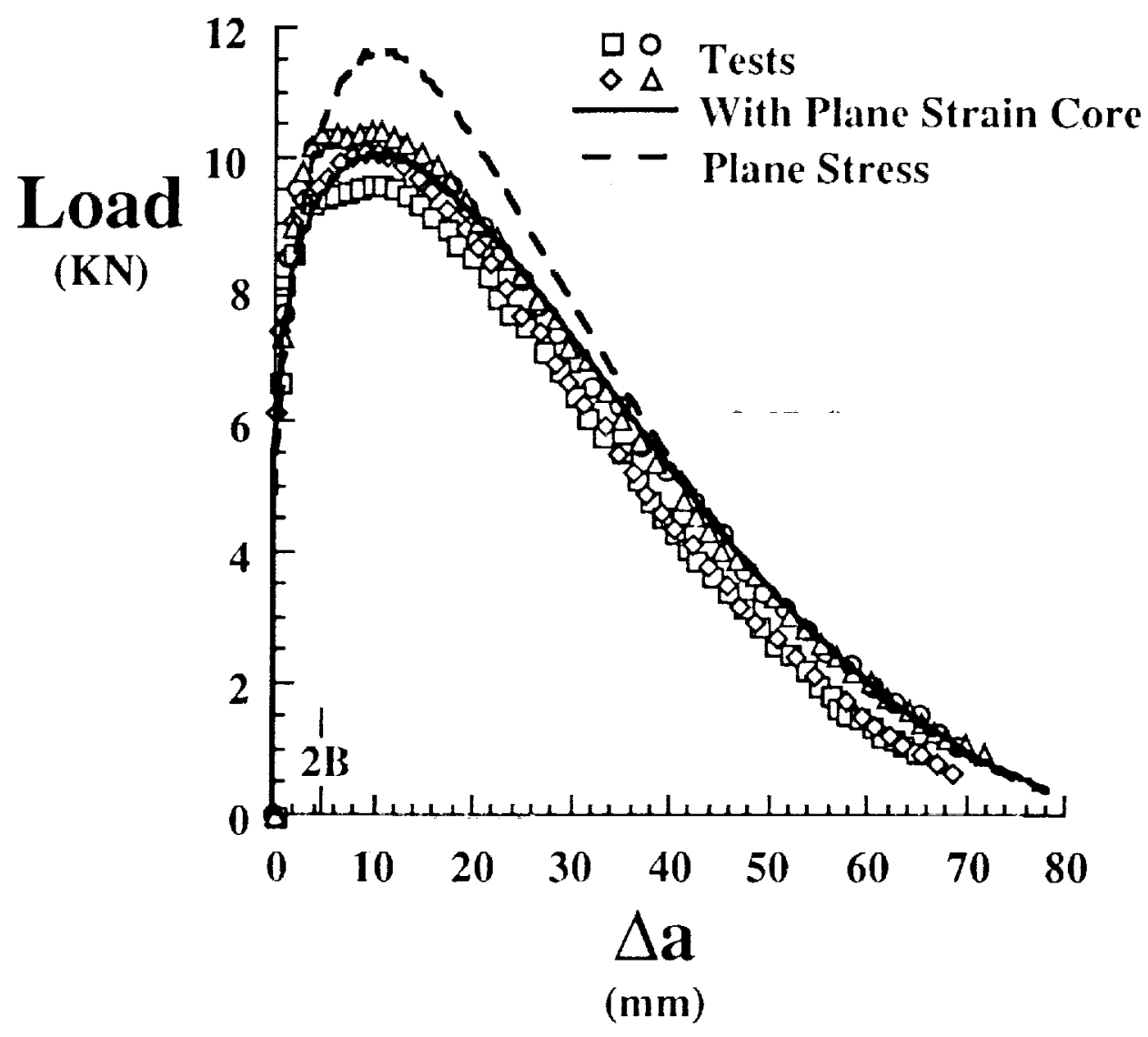

Figure 13. The experimentally measured crack extension as a function of applied load and the two-dimensional, finite element analysis calculation for four $\mathrm{C}(\mathrm{T})$ lests. 


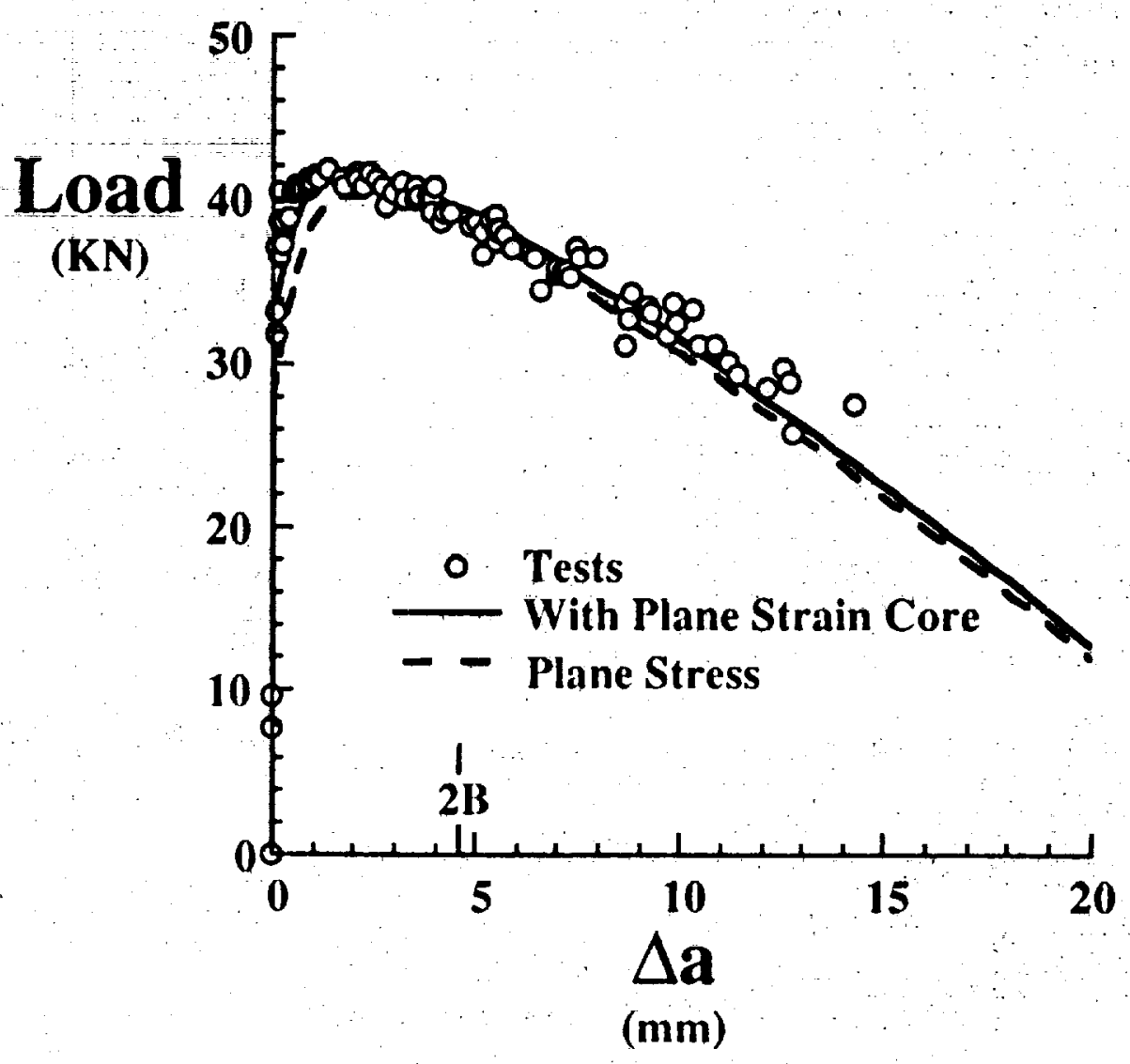

Figure 14. The experimentally measured crack extension as a function of applicd load and the two-dimensional, linite element analysis calculation for the thirteen $M(T)$ tests. 


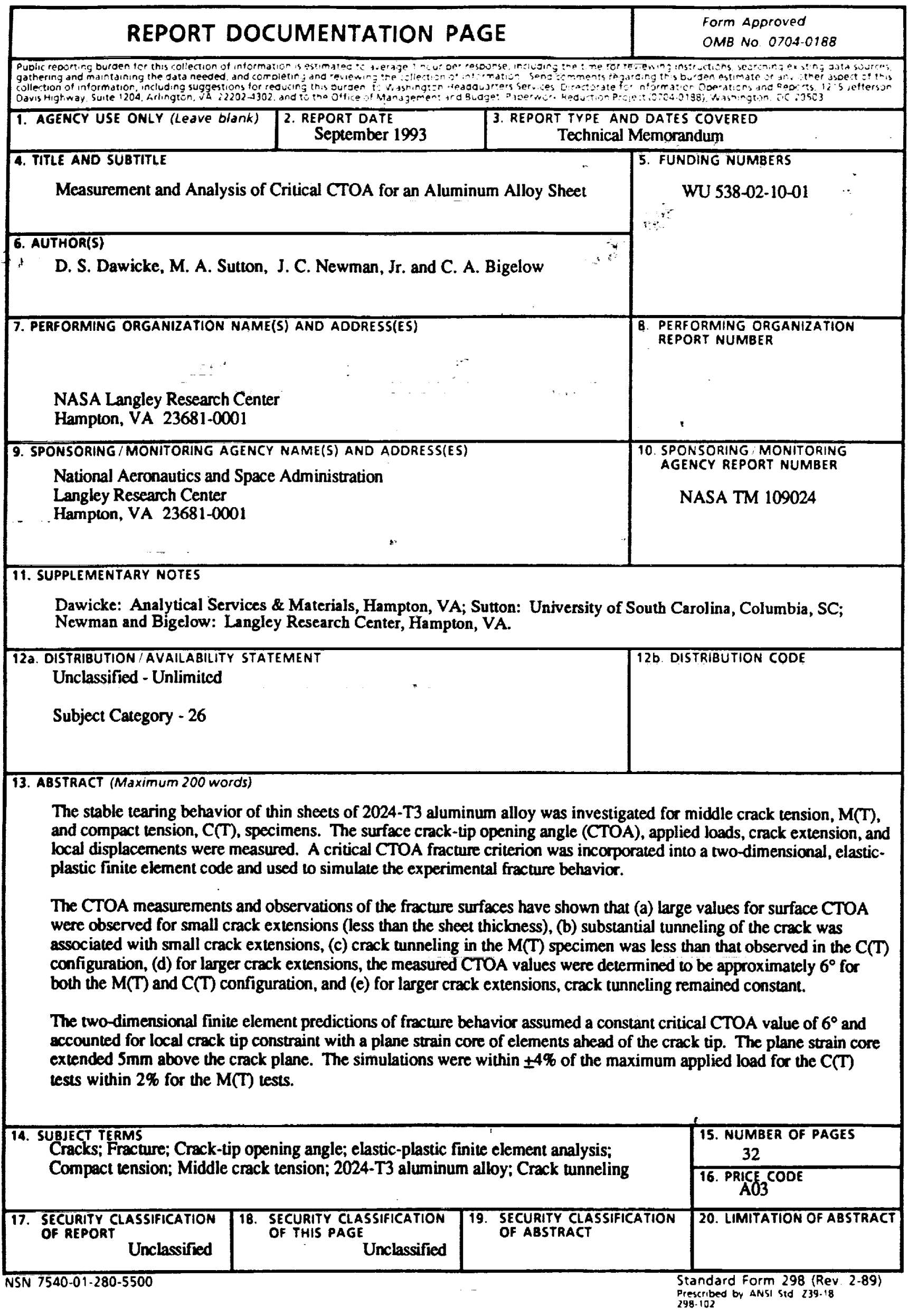

